\title{
Working from home and income inequality: risks of a 'new normal' with COVID-19
}

\section{Luca Bonacini ${ }^{1} \cdot$ Giovanni Gallo ${ }^{1,2} \cdot$ Sergio Scicchitano ${ }^{2,3}$}

Received: 27 May 2020 / Accepted: 19 August 2020 / Published online: 12 September 2020

(C) Springer-Verlag GmbH Germany, part of Springer Nature 2020

\begin{abstract}
In the current context of the COVID-19 pandemic, working from home (WFH) became of great importance for a large share of employees since it represents the only option to both continue working and minimise the risk of virus exposure. Uncertainty about the duration of the pandemic and future contagion waves even led companies to view WFH as a 'new normal' way of working. Based on influence function regression methods, this paper explores the potential consequences in the labour income distribution related to a long-lasting increase in WFH feasibility among Italian employees. Results show that a positive shift in WFH feasibility would be associated with an increase in average labour income, but this potential benefit would not be equally distributed among employees. Specifically, an increase in the opportunity to WFH would favour male, older, high-educated, and high-paid employees. However, this 'forced innovation' would benefit more employees living in provinces have been more affected by the novel coronavirus. WFH thus risks exacerbating pre-existing inequalities in the labour market, especially if it will not be adequately regulated. As a consequence, this study suggests that policies aimed at alleviating inequality, like income support measures (in the short run) and human capital interventions (in the long run), should play a more important compensating role in the future.
\end{abstract}

Keywords COVID-19 $\cdot$ Working from home $\cdot$ Inequality $\cdot$ Unconditional quantile regressions

JEL Classification D31 $\cdot \mathrm{J} 31 \cdot \mathrm{I} 24$

Responsible editor: Klaus F. Zimmermann

Sergio Scicchitano

s.scicchitano@inapp.org; https://sergioscicchitano.wordpress.com

1 University of Modena and Reggio Emilia, Modena, Italy

2 National Institute for Public Policies Analysis (INAPP), Corso d'Italia 33, 00198 Rome, Italy

3 Global Labour Organisation (GLO), Essen, Germany 
'That push [related to reopening decisions during the pandemic] is likely to exacerbate longstanding inequalities, with workers who are college educated, relatively affluent and primarily white able to continue working from home and minimising outdoor excursions to reduce the risk of contracting the virus'

The New York Times, 27 April 2020 (https://www.nytimes.com/2020/04/27 /business/economy/coronavirus-economic-inequality.html)

\section{Introduction}

The COVID-19 pandemic is raging worldwide and probably will not end in the short term, possibly resulting in structural effects on the labour market in many countries (Baert et al. 2020a). In order to limit the number of deaths and hospitalisations due to the novel coronavirus, most governments in developed countries decided to suspend many economic activities and restrict people's freedom of mobility (Brodeur et al. 2020a, b; Qiu et al. 2020).

In this context, the opportunity to work from home (WFH) became of great importance (Acemoglu et al. 2020) since it allows employees to continue working and thus receiving wages, employers to keep producing services and revenues, and overall limits infection spread risk and pandemic recessive impacts. Recent estimates for the USA show that remote workers have quadrupled to $50 \%$ of US workforce (Brynjolfsson et al. 2020). Due to uncertainty about the duration of the pandemic and future contagion waves, the role of WFH in the labour market is further emphasised by the fact that it might become a traditional (rather than unconventional) way of working in many economic sectors. According to Alon et al. (2020, p. 17), 'Many businesses are currently adopting work-from-home and telecommuting options at a wide scale for the first time. It is likely that some of these changes persist, leading to more workplace flexibility in the future'. Also, Baert et al. (2020b) recently found that the great majority of the employees believe that teleworking (85\%) and digital conferencing (81\%) will continue after the SARS-CoV-2 crisis. Facebook and a number of other companies, especially those dealing with information technology (IT), have already decided they will allow many employees to work from home permanently. ${ }^{1}$

Because of WFH's sudden prominence and growth, several studies recently investigated the WFH phenomenon, especially with the objective of identifying the number of jobs that can be done remotely (Adams-Prassl et al. 2020; Dingel and Neiman 2020; Koren and Peto 2020; Leibovici et al. 2020; Mongey et al. 2020). However, the literature neglects potential effects of WFH along the wage distribution and on income inequality in general. As we know, the causes of inequalities are heterogeneous and numerous, and these causes have been growing in prominence in policymakers'

\footnotetext{
${ }^{1}$ Specifically, Mr. Zuckerberg stated: 'It's clear that COVID has changed a lot about our lives, and that certainly includes the way that most of us work. Coming out of this period, I expect that remote work is going to be a growing trend as well' (see, https://www.nytimes.com/2020/05/21/technology/facebook-remote-workcoronavirus.html).
} 
debates because inequality has increased in Western countries over the last decades (Atkison 2015; Beckfield 2019).

To the best of our knowledge, this study represents the first to show how a future increase in WFH would be related to changes in labour income levels and inequality, through the influence function regression method proposed by Firpo et al. (2009). In particular, we want to understand to what extent an increase in the number of employees who have the opportunity to WFH (or at least their professions are more likely to be performed from home) would influence the wage distribution under the hypothesis that this WFH feasibility shift is long lasting (as it seems it will happen because of the COVID-19 outbreak and its aftermath). Considering baseline feasibility levels across Italian employees as the counterfactual scenario, the Firpo et al.'s (2009) methodology allows us to estimate potential influences of this 'innovation' on labour income inequality moving toward a hypothetical distribution where shares of employees are swapped with others according to the reported WFH feasibility level. With respect to the (conventional) quantile regression method developed by Koenker and Bassett (1978), this methodology has also the merit of estimating the effects on a labour income distribution that is not conditioned by the set of covariates included in the model (Fortin et al. 2011).

To do that, we focus on Italy as an interesting case study because it was one of the countries most affected by the novel coronavirus and the first Western country to adopt a lockdown of economic activities (on 11 March). Barbieri et al. (2020) estimated that at least 3 million employees (i.e. about $13 \%$ of the total) started to WFH because of lockdown measures, and another large number started even earlier due to the closure of schools and universities on 5 March (more details in Bonacini et al. 2021). Moreover, Italy was the European country with the lowest share of teleworkers before the crisis (Eurofound and ILO 2017) and, as a result of the pandemic, it had to face a massive increase in WFH in a very short time without both precise legislation and adequate policies. Now that the country is steadily increasing the share of WFH, it is crucial to understand the possible effects on the labour market of such a structural change.

Our analysis relies on a uniquely detailed dataset relying on the merge of two sample surveys. The first one is the Survey on Labour Participation and Unemployment (INAPP-PLUS) for the year 2018, which contains information on incomes, skills, education level, and employment conditions of working-age Italians. The second sample survey is the Italian Survey of Professions (ICP) for the year 2013, which represents an Italian equivalent of the much more famous US Occupational Information Network $\left(\mathrm{O}^{*} \mathrm{NET}\right)$. ICP provides detailed information on the task-content of occupations at the 5-digit ISCO classification level and allows to calculate the WFH index recently proposed by Barbieri et al. (2020). Different from other studies that analyse working from home in Italy through an elaborated matching between US O*NET data and Italian labour market information (e.g. Boeri et al. 2020), we use ICP data to avoid potential matching biases. In fact, being based on professions performed in the Italian labour market, ICP has the key advantage of being probably more able than the US O*NET to capture specific features (e.g. tasks, skills required, workplace characteristics) of the Italian economy.

To provide further insights on the relationship between a WFH shift and labour income inequality, we also estimate heterogeneous effects by gender, age group, and education level. The latter is particularly interesting because it allows us to test whether 
an increase in WFH among high-skilled and educated employees may be related to Skill Biased Technological Change (SBTC) (Acemoglu 2002; Autor et al. 2003). In this context, the existing complementarity between new technologies and high-paid professions may be a key factor in wage polarisation, which in turn is the key variable to understand, predict, and manage some of the possible long-run consequences of COVID-19 in terms of working modality changes. Moreover, we merge our dataset with one provided by the Italian Civil Protection Department (2020) on COVID-19 infection spread at the provincial level (reference period 24 February-5 May 2020) to investigate whether this potential increase in WFH would benefit more those areas of the country that have been affected the most by the novel coronavirus and thus will suffer worse economic consequences.

Finally, this study has relevant policy implications for tackling inequalities that will arise in the labour market because of the recent pandemic and the consequent (probably) increase in WFH. Our results are based on Italian data, but they may be useful to policymakers in other developed countries as well and, in general, where COVID-19 has forced governments to rethink production processes with a more intense and stable use of WFH.

The rest of the article is structured as follows. The next section presents the literature review on the topic and a brief chronicle of the COVID-19 outbreak in Italy. Section 3 describes the datasets, discusses the definition of our variables of interest, and provides some descriptive statistics, while Sect. 4 reports the econometric methodology. Sections 5 and 6 present results and robustness checks. Section 7 concludes with some policy implications.

\section{Conceptual framework and existing evidence}

\subsection{Work from home and inequality: previous and current literature}

Flexible work practices (Leslie et al. 2012) and WFH have already been studied in normal times (e.g. Blinder and Krueger 2013; Bloom et al. 2015). Empirical economics literature suggests that there are theoretical reasons to associate both higher and lower wages to teleworkers with respect to 'traditional workers'. As a result, the link between WFH and income inequality is still ambigous and under debate. On the one hand, lower wage levels may be due to a lower productivity of employees performing their occupation from home (Dutcher and Saral 2012). A reduction of wage may also be due to a lower disutility of WFH as a consequence of attending child and elderly care, time flexibility, and lower commuting expenses (Bélanger 1999). On the other hand, the adoption of telework may generate a costs reduction for firms which, in turn, may be translated in higher wages (Hill et al. 1998). Pabilonia and Vernon (2020) find that some teleworkers in the USA earn a higher wage than the other workers, but results vary by occupation, gender, parental status, and teleworking intensity. Recent studies conducted in the USA also find a high correlation between high income levels and high-speed Internet, thus meaning that WFH is easier for relatively rich people (Chiou and Tucker 2020). As for Italy, to our knowledge, only Pigini and Staffolani (2019) deal with the average wage gap between teleworkers and employees making traditional jobs. Their study highlights that the small number of teleworkers in the labour market 
(1\% of total), after accounting for observed individual and job-specific variables, enjoy an average wage premium ranging between 2.7 and $8 \%$.

Even for the gender pay gap, although widely studied, there is not a clear evidence of the effect of WFH. Gariety and Shaer (2007), Bloom et al. (2015), Arntz et al. (2019), and Angelici and Profeta (2020) point out that WFH may reduce (or at least not increase) wage differences between male and female workers. On the other hand, Weeden (2005), Goldin (2014), and Bertrand (2018) display results in the opposite direction.

The economic literature on COVID-19 is exploding daily: between March 2020 and June 2020, the Bureau of Economic Research (NBER) released more than 160 working papers on this topic and around 100 were the discussion papers published by the IZA Institute of Labor Economics (Brodeur et al. 2020c). Similarly, the Global Labour Organisation (GLO) Cluster Coronavirus published more than 30 discussion papers on the economics of COVID-19. A large number of articles investigated the consequences of the virus spread on the labour market in different countries (Béland et al. 2020a; Bennedsen et al. 2020; Bertocchi and Dimico 2020; Duman 2020; Greyling et al. 2020; Milani 2021; Nikolova and Popova 2020). Within this strand of increasing current literature, several studies recently analysed the WFH phenomenon because of its sudden growth of prominence.

Most of these studies (see, for instance, Béland et al. 2020b; Dingel and Neiman 2020; Gottlieb et al. 2020; Hensvik et al. 2020; Holgersen et al. 2020; Koren and Peto 2020; Leibovici et al. 2020; Yasenov 2020) aim to classify occupations according to their WFH feasibility in the USA and some European countries (e.g. UK, Germany), as well as in Latin American and Caribbean countries (Delaporte and Pena 2020). Papanikolaou and Schmidt (2020) examine differences in the opportunity of workers across industries to have WFH using data from the American Time Use Survey (ATUS). As for Italy, Boeri et al. (2020), relying on the US O*NET dataset, estimate that $24 \%$ of jobs can be carried out from home, while Barbieri et al. (2020) rank sectors and occupations according to the risk of contagion and propose an indicator of WFH feasibility to understand in which sectors this risk can be reduced without any interruction from working. However, they ignore the possible distributional consequences of a steady increase in working remotely. In this paper, we instead show the potential relationship between a positive shift in the WFH feasibility of employees and labour income inequality over the whole distribution, also distinguishing by individual characteristics.

\subsection{COVID-19 outbreak in Italy}

To expose the chronicle of the COVID-19 pandemic in Italy, we begin in Wuhan, a city in Eastern China, where in December 2019 several persons affected by a severe acute respiratory syndrome were reported. Scientists identified the cause of this pneumonia in a novel strain of coronavirus, that the World Health Organisation named SARS-CoV-2. The disease, designated as COVID-19, caused more than 85 thousand confirmed deaths in China showing a great rate of spread.

To prevent the outbreak in Italy, on 30 January 2020 (i.e. the same day two Chinese tourists tested positive for COVID-19 and were hospitalised in Rome), the national government implemented the first restrictive measures: it declared the state of 
emergency and it blocked all flights to and from China. As a recent study by Zimmermann et al. (2020) highlighted, the contagion speed of the novel coronavirus seems to be also favoured by globalisation and, despite measures adopted in Italy, on February 21, a cluster of cases was discovered in the Lombardy region. Despite the attempt of the Italian government to isolate the cluster declaring 'red areas' all municipalities counting COVID-19 infected, the virus has spread throughout the country and on 23 February, Italy became the European country with the highest number of registered positive cases.

The government reacted to the emergency implementing a series of increasingly stringent rules intended to prohibit the areas of aggregation and to avoid contacts between people. It has been the first European country to implement courageous acts to restrict citizens' mobility. On 4 March, the Prime Minister signed a law forcing the closure of schools and universities and the stoppage of all sporting and social events from 5 March, with the initial aim (and hope) of reopening in 10 days. On 8 March, the Italian government implemented another extraordinary restrictive measure declaring as red areas, all the Lombardy region and other 14 northern provinces ${ }^{2}$. Due to the worsening situation, only 3 days after (i.e. 11 March, the day-after World Health Organisation declared the situation of global pandemic), the government compelled all commercial and retail businesses to close down, with the exception of those referred to basic necessities. Even food services (e.g. bars, restaurants) were forced to close and eventually provide takeaway services only. Around 2.7 million workers suspended their activity (Barbieri et al. 2020).

The last important containment measure adopted focused on the closure of all 'nonessential' economic activities, but it followed a different path compared with the previous ones. A first version of the regulation was announced on 21 March and published on 22 March, but it was modified on 25 March after the meeting between the Government, unions, and representation of the entrepreneurs. The final law tightened the measures in several ways, including the following: the suspension of every activity furnishing food, the closure of every professional activity or self-employment, and restrictions on people's mobility freedom. After these amendments, around 8 million workers (34\% of total) were forced to stay home (Barbieri et al. 2020).

On 4 May, 'Phase 2' of coexistence with the COVID-19 virus began. It consisted of a progressive reduction of lockdown measures introduced during 'Phase 1' (i.e. the epidemic phase), as well as those measures regarding the mobility freedom of population. The transition from the epidemic phase to Phase 2 was subordinated to the institutions' ability to diagnose, manage, and isolate COVID-19 cases and their contacts. Entrepreneurial and some other business activities could only reopen under precise conditions and much of normal life could resume with caution. For instance, physical distancing rules must be respected, collective demonstrations must be avoided, and concrete protection must be given to vulnerable subjects. Moreover, public hygiene must be radically improved and individual protection methods (e.g. masks) and systematic and routine cleaning of public spaces must be provided. The containment measures also concern: individual and collective limitations to mobility (local, medium and long distance); the supply and distribution of protective equipment (personal

\footnotetext{
${ }^{2}$ In this regard, recent accurate estimates have shown that one should be cautious before considering Lombardy as a 'special' case (Depalo 2021).
} 
protective equipment); tracing infectious cases, with massive identification plans for primary and secondary infections; and the implementation of different levels of administrative and environmental engineering controls.

\subsection{Working from home in Italy: before, during, and after the COVID-19}

During the pandemic period, many of measures regarding occupations and social distancing were linked to WFH. In fact, giving the opportunity of working remotely to employees limited their movements outside home and the risk of COVID-19 exposure in general, without interruptions (or at least small ones) on tasks generally performed and on consequent earnings. To easily allow the WFH for public sector employees, a momentary simplification of rules applied to public tenders for laptops purchases was even introduced. However, several income supports to quarantined employees who could not work from home was guaranteed, such as a replacement income (almost) totally financed by public resources (i.e. Cassa Integrazione Guadagni), a lump sum benefit of 600 euro for self-employed, seasonal, and agricultural employees, an extension of unemployment benefits, and the suspension of dismissals for economic reasons. ${ }^{3}$

The opportunity to remain in a WFH status was confirmed in the Phase 2 for the majority of workers who have been involved in such condition during the lockdowns, and nowadays, this way of working is still strongly encouraged. Before the COVID-19 pandemic, however, the WFH practice in Italy was definitely not widespread and frequently the notions of teleworking and WFH (or smart working) were used interchangeably. The most representative Italian trade unions - the Italian General Confederation of Work (Confederazione Generale Italiana del Lavoro (CGIL)), the Italian Confederation of Workers' Unions (Confederazione Italiana Sindacati Lavoratori (CISL)), and the Union of Italian Workers (Unione Italiana del Lavoro (UIL)) - usually call for the adoption of teleworking in order to improve the quality of work-life balance policies for workers whose residence is very far from the workplace or for those who have to provide care to young children or relatives with disabilities (Eurofound and ILO 2017).

In the Italian regulation, the telework implies the indication of times and location outside the office (Ichino 2020a). Instead, the Law n. 81/2017 (the so-called Jobs Act of self-employment), concerning 'Measures for the protection of self-employed nonentrepreneurial work and measures aimed at promoting flexible articulation in the times and places of subordinate work', which officially introduced the smart working (or Lavoro agile) in the Italian regulation, defines the smart work as an activity that, although carried out in a subordinate regime, is characterised by the absence of constraints on where and when the same is performed. Therefore, the smart work of WFH substantially differs from the telework, but the recent regulation has been actually applied in very few cases. More specifically, it deals with Chapter II 'Agile work' (articles 18-23). Company agreements that also include WFH are very few, although growing in recent years. Currently, collective agreements clearly dealing with WFH are

\footnotetext{
${ }^{3}$ Beyond these measures and the existing minimum income scheme (i.e. the Citizenship Income or Reddito di Cittadinanza), a means-tested 'emergency income' (Reddito di Emergenza) was introduced to deal with households with economic distress but not eligible to all other income support measures. Further employment and social initiatives introduced in Italy (and other developed countries) at the time of COVID-19 outbreak are available here: https://www.oecd.org/coronavirus/country-policy-tracker/.
} 
only present in the food, energy, and banking-insurance sectors. There are also unilateral initiatives of high-tech companies aimed above all at higher professional figures (Tiraboschi 2017). Recent estimates report that, among EU-28 countries, Italy shows the lowest share of employed which have the opportunity of WFH (Eurofound and ILO 2017). Using the Italian Labour Force Survey (LFS) for the period 20082013, Pigini and Staffolani (2019) find that only 1\% of workers are 'teleworkers', defined as those who WFH at least twice per week.

Because WFH is not popular in Italy, it is difficult to provide reliable estimates on how and to what extent this phenomenon affects the labour market except through experimental studies (an interesting example is the one provided by Angelici and Profeta 2020). For this reason, we decided to investigate the feasibility to WFH under the hypothesis that the recent crisis related to the COVID-19 outbreak has determined a structural change in the use of this tool. In fact, consequently to the pandemic, WFH became much more popular and could turn into one ordinary way of working after the crisis. The Budget Committee of the Italian Parliament has approved an amendment in June 2020 which obliges public administrations to plan WFH for at least 50\% 'of the activities that can be carried out in this way' by the end of this year, $60 \%$ thereafter. On 17 June, the Minister of Public Administration declared that $90 \%$ of public sector employees were engaged in WFH during Phase 1, reporting on average an increase of productivity rates. Moreover, by the end of 2020, the same Minister intends to survey activities that can be carried out remotely, with the objective of moving forward a stable use of WFH in about $50 \%$ of them (Ichino 2020b). In this article, we want to analyse effects that this 'forced innovation' would have on the labour market of a developed country. In particular, this study aims to underscore whether the potential increase (decrease) in the average labour income related to a positive shift in the WFH feasibility levels (e.g. because of a change in productivity) would be equally distributed throughout the wage distribution and among groups of employees or not.

\section{Data and descriptive statistics}

Our analysis relies on an innovative dataset recently built by merging two Italian surveys, developed and provided by the Italian National Institute for the Analysis of Public Policies (INAPP). The first one is the Participation, Labour and Unemployment Survey (PLUS), which provides reliable statistics on labour market phenomena that are rare or marginally explored by the much more known Labour Force Survey (LFS) by Eurostat. The INAPP-PLUS survey also contains information on a wide range of standard individual characteristics, as well as numerous characteristics related to professions and firms, for approximately 45,000 individuals in each wave. We use the (last) eighth wave of the survey which was collected in 2018 and released in the first half of 2019. A dynamic computer-assisted telephone interview (CATI) approach was used to distribute the questionnaire to a sample of residents aged between 18 and 74 according to a stratified random sampling over the Italian population. ${ }^{4}$ One of the key

\footnotetext{
${ }^{4}$ The stratification of the INAPP-PLUS survey sample is based on population strata by NUTS-2 region of residence, urbanisation degree (i.e. metropolitan or non-metropolitan area), age group, sex, and employment status (i.e. employed, unemployed, student, retired, or other inactive status).
} 
elements of this dataset is the absence of proxy interviews: in the survey, only survey respondents are reported, to reduce measurement errors and partial non-responses. However, the INAPP-PLUS survey provides individual weights to account for nonresponse and attrition issues which usually affect sample surveys. Similarly to other empirical studies relying on the same dataset (see, among others, Clementi and Giammatteo 2014; Filippetti et al. 2019; Meliciani and Radicchia (2011, 2016), all descriptive statistics and estimates reported in this analysis are weighted using those individual weights. ${ }^{5}$

The second survey composing our innovative dataset is the 2013 wave of the ICP, created in 2004 and currently performed by INAPP. The ICP integrates the traditional approach by focusing on nature and content of the work. It aims to describe with a high analytical detail all existing professions in terms of, on the one hand, requirements and characteristics required to the worker and, on the other hand, activities and working conditions each profession implies. It was chosen to involve workers rather than experts, privileging the point of view of those who exercise daily professions analysed and have a direct and concrete assessment of the level of use of certain characteristics essential to accomplish the job. The survey reports information on about 16,000 workers and describes all the 5-digit occupations (i.e. 811 occupational codes) existing in the Italian labour market, from those operating in private companies to those present within public institutions and structures, up to those operating under autonomy.

The conceptual reference framework for the investigation and the taxonomies of variables used in the ICP survey are borrowed from the US model of the O*Net, because it is the most complete in terms of the job description and the ablest to comprehensively respond to potential stakeholder questions. Following to the US O*Net conceptual model, ICP questions explore each profession as a multi-dimensional concept that can be described referring to these four thematic areas: (a) worker requirements (e.g. skills, knowledge, educational level); (b) worker characteristics (e.g. traits, working styles); (c) profession requirements (i.e. generalised work activities and working context); and (d) experience requirements (i.e. training and experience). Remarkably, Italy is one of few European countries to have a dictionary of occupations similar to the US O*NET. Taking advantage from this feature, as it is based on the Italian dictionary of occupations rather than the US one, ICP appears more reliable in capturing the production structure, technology and industrial relations characterising the Italian economics. Since our analysis relies on ICP data, we should thus avoid potential biases arising when matching information linked to occupational structures (e.g. those contained in the US O*Net repertoire) and labour markets of different countries. To be noted, the existing literature on automation (Goos et al. 2014) and recent contributions on WFH in Italy (Boeri et al. 2020) use instead US O*Net data, making a sophisticated 'bridge' between US and European (and Italian in particular) occupations which possibly reflects US-specific technology and ways of working.

From the total INAPP-PLUS sample (45,000 observations), to develop our analysis, we drop 25,064 people with no occupation (e.g. students, retires, unemployed). Then, as usual in empirical studies focusing on labour market phenomena, we apply an age

\footnotetext{
${ }^{5}$ As a sensitivity analysis, we replicated all estimates in our main analysis without applying individual weights. Results of this check, presented in Sect. 6, overall confirm the robustness of our main results presented in Sect. 5 .
} 
restriction to our sample, further excluding from the analysis individuals who are not aged 25-64 years old (1220 observations). We also decided to drop self-employed from our sample (3741 observations) for two main reasons. ${ }^{6}$ First, because their strong within-heterogeneity, related to several aspects such as the application of different regulations, may overall affect our estimates. (To give a better idea, note that in our analysis sample the Gini index of the annual gross labour income is equal to 0.444 among self-employed and 0.280 among employed.) Second, the potential unclarity in the usage of working from home procedures by self-employed, as they tend to perform multiple different tasks and do not have a subordinate role, may make considerations coming out from this analysis overall less clear. We finally drop further 668 observations with missing values in relevant variables. Our analysis sample of employees therefore counts 14,307 observations.

\subsection{Definition of the feasibility to work from home}

The ICP survey includes questions that are helpful to evaluate the feasibility to work from home of Italian workers, which is particularly relevant in the current COVID-19 emergency. To this end, we adopt the same WFH feasibility index recently proposed by Barbieri et al. (2020), which is calculated for each 5-digit profession and ranges from a 0 (WFH is not essentially possible) to 100 (WFH is very easily possible). As the feasibility of an occupation of being performed from home is related to multiple dimensions regarding the specific task, this index is computed by taking into account replies to the following seven questions: (i) importance of working with computers; (ii) importance of performing general physical activities (which enters reversely); (iii) importance of manoeuvring vehicles, mechanical vehicles or equipment (reversely); (iv) requirement of face-to-face interactions (reversely); (v) dealing with external customers or with the public (reversely); (vi) physical proximity (reversely); and (vii) time spent standing (reversely). For each item, replies of workers are overall standardised to an index with a $0-100$ range. The WFH feasibility index proposed by Barbieri et al. (2020) is then calculated through a simple average of these seven indexes. In other words, the WFH feasibility index here adopted consists of a multidimensional index where all the seven dimensions are equally weighted. The index is finally aggregated at the ISCO 4-digits level to allow this information to be merged with INAPP-PLUS data.

Once the WFH feasibility index is included in our analysis sample, it ranges from 8.8 to 85.0 and presents a median value of 52.2 and a mean value of 52.4. Although this index is provided as continuous variable, we preferred not to use it in this specification but by feasibility levels. Two of the main drawbacks of using a multidimensional index are indeed that it tends to report a skewed distribution and its specific values can be hardly interpreted. Rather, beyond allowing to consider different aspects together, this type of index allows to rank individuals (in this case, workers by the WFH feasibility of their professions) giving more importance to their relative position in the distribution than the absolute distance between observations. For this reason, we decided to define

\footnotetext{
${ }^{6}$ As a sensitivity analysis, we however replicated our main analysis on a sample including self-employed individuals aged 25-64 years old and with no missing values in relevant variables. Results of this check, presented in Sect. 6, overall confirm the robustness of our main results presented in Sect. 5.
} 
our variable of interest as a dummy taking value 1 (i.e. high level of WFH feasibility) for employees reporting a value of the multidimensional index over the sample median, and 0 otherwise (i.e. low level of WFH feasibility).

As regards the specification of our variable of interest, we however developed in Sect. 6 several robustness checks on results of the main analysis. Specifically, we replaced the dummy specification of the WFH feasibility variable with a continuous one, as well as with a quintile, quartile or tertile groups specification. Also, keeping constant the dummy specification, we changed the definition of the WFH feasibility variable making it take value 1 over the sample mean (rather than the median) or $60 \%$ of the sample mean. Results of all these tests highlight essentially the same conclusions of our main analysis, thus confirming its robustness. Finally, as to provide further insights on the potential effect of a positive shift in the WFH feasibility of professions on the wage distribution, we replicate our main analysis using as variable of interest the single items composing the adopted multidimensional index. Results of this thorough investigation are presented in Sect. 5.3.

\subsection{Descriptive statistics}

Table 1 shows some preliminary statistics about the sample composition, values of mean and Gini index of annual gross labour income, mean value of the WFH feasibility index and share of employees with high feasibility level by group of employees. Detailed descriptions of variables used in the analysis are provided in Appendix Table 7, while Appendix Table 8 illustrates the same information of Table 1 by activity sector in which employees work.

Table 1 highlights that employees in our sample appear to be more often males, aged 36-50, with an upper secondary education, local, and married. They live in households with more than four members in $37 \%$ of cases and with at least one minor child in $34 \%$ of cases. They tend to be located in small municipalities (i.e. cities with 5000-20,000 inhabitants) and in the North of Italy, have more frequently a full-time open-ended contract and work in the private sector.

Focusing on labour income differences at 5\% level only, Table 1 shows that employees with high WFH feasibility report on average a higher labour income than those doing an occupation with low feasibility levels. Also, employees appear to meanly receive a higher income if male, older (i.e. aged 51-64), graduated, married, live in northern regions, full-time open-ended worker, or public servant. At the opposite, employees living in households with three members tend to report a significantly lower labour income with respect to the others. ${ }^{7}$

Table 1 points out that groups of employees with higher labour income often report a greater within-level of income inequality too (i.e. higher values of Gini index), with few exceptions. For example, in this case, greater inequality levels are presented by employees with a lower secondary education (or lower), those living in bigger

\footnotetext{
${ }^{7}$ Preliminary evidence confirms that differently from the USA, where workers in high productivity areas tend to receive high salaries (see Hornbeck and Moretti 2018), in Italy wage differentials between small and big cities are not significant. Recent estimates find that the urban wage premium is zero in nominal terms and even negative and non-negligible in real terms (Belloc et al. 2019).
} 
Table 1 Sample composition, mean, and Gini index of annual labour income, mean value of the WFH feasibility index, and share of employees with high feasibility level by group of employees

\begin{tabular}{|c|c|c|c|c|c|c|}
\hline \multirow[t]{2}{*}{ Variable } & \multicolumn{2}{|c|}{$\begin{array}{l}\text { Sample } \\
\text { composition }\end{array}$} & \multicolumn{2}{|c|}{$\begin{array}{l}\text { Annual labour } \\
\text { income }\end{array}$} & \multicolumn{2}{|c|}{ WFH feasibility } \\
\hline & Mean & Std. Dev. & Mean & Gini index & Mean & $\begin{array}{l}\% \text { of employees } \\
\text { with high feasibility }\end{array}$ \\
\hline Low WFH feasibility & 0.518 & 0.500 & 24,731 & 0.261 & 40.5 & 0.0 \\
\hline High WFH feasibility & 0.482 & 0.500 & 27,320 & 0.296 & 65.1 & 100.0 \\
\hline Male & 0.537 & 0.499 & 29,321 & 0.283 & 52.3 & 45.3 \\
\hline Female & 0.463 & 0.499 & 22,098 & 0.256 & 52.5 & 51.5 \\
\hline Ages $25-35$ & 0.204 & 0.403 & 21,962 & 0.257 & 51.7 & 46.9 \\
\hline Ages $36-50$ & 0.467 & 0.499 & 26,146 & 0.279 & 52.5 & 47.9 \\
\hline Ages 51-64 & 0.329 & 0.470 & 28,232 & 0.282 & 52.5 & 49.4 \\
\hline Lower secondary education (or lower) & 0.313 & 0.464 & 23,500 & 0.284 & 46.7 & 27.4 \\
\hline Upper secondary education & 0.464 & 0.499 & 25,670 & 0.267 & 54.6 & 54.7 \\
\hline Tertiary education & 0.224 & 0.417 & 30,082 & 0.277 & 55.8 & 63.7 \\
\hline Local & 0.882 & 0.322 & 25,912 & 0.276 & 52.4 & 48.4 \\
\hline Migrant within macro-region & 0.031 & 0.173 & 28,434 & 0.360 & 53.2 & 52.1 \\
\hline Migrant within country & 0.066 & 0.248 & 26,839 & 0.276 & 52.8 & 51.5 \\
\hline Foreign migrant & 0.021 & 0.143 & 22,429 & 0.306 & 48.2 & 22.8 \\
\hline Unmarried & 0.429 & 0.495 & 24,045 & 0.261 & 52.3 & 47.6 \\
\hline Married & 0.571 & 0.495 & 27,432 & 0.290 & 52.4 & 48.6 \\
\hline Household size $=1$ & 0.141 & 0.348 & 26,961 & 0.269 & 53.4 & 48.9 \\
\hline Household size $=2$ & 0.202 & 0.401 & 25,973 & 0.284 & 52.1 & 48.1 \\
\hline Household size $=3$ & 0.283 & 0.450 & 24,772 & 0.258 & 52.5 & 48.8 \\
\hline Household size $=4$ & 0.291 & 0.454 & 26,574 & 0.289 & 52.6 & 49.0 \\
\hline Household size $=5$ or more & 0.083 & 0.276 & 26,349 & 0.325 & 50.1 & 42.3 \\
\hline Absence of minors & 0.657 & 0.475 & 25,770 & 0.285 & 52.4 & 48.4 \\
\hline Presence of minors & 0.343 & 0.475 & 26,378 & 0.270 & 52.4 & 47.7 \\
\hline Very small municipality & 0.206 & 0.404 & 25,394 & 0.270 & 50.9 & 41.4 \\
\hline Small municipality & 0.329 & 0.470 & 26,376 & 0.285 & 51.5 & 45.2 \\
\hline Medium municipality & 0.159 & 0.366 & 25,668 & 0.269 & 52.3 & 48.1 \\
\hline Big municipality & 0.167 & 0.373 & 26,196 & 0.300 & 53.1 & 52.6 \\
\hline Metropolitan city & 0.139 & 0.346 & 25,998 & 0.269 & 55.9 & 60.3 \\
\hline North & 0.538 & 0.499 & 26,666 & 0.267 & 52.4 & 47.1 \\
\hline Centre & 0.214 & 0.410 & 24,911 & 0.267 & 53.6 & 53.2 \\
\hline South & 0.248 & 0.432 & 25,410 & 0.317 & 51.3 & 46.1 \\
\hline Full-time open-ended worker & 0.695 & 0.461 & 29,225 & 0.240 & 53.0 & 48.9 \\
\hline Part-time open-ended worker & 0.153 & 0.360 & 17,527 & 0.293 & 52.7 & 52.7 \\
\hline Temporary worker and other & 0.152 & 0.359 & 19,659 & 0.310 & 49.4 & 40.3 \\
\hline Private sector employee & 0.700 & 0.458 & 25,443 & 0.301 & 52.7 & 47.8 \\
\hline Public servant & 0.300 & 0.458 & 27,228 & 0.228 & 51.5 & 49.1 \\
\hline Total sample & - & - & 25,979 & 0.280 & 52.4 & 48.2 \\
\hline
\end{tabular}

Notes: All descriptive statistics are computed with individual sample weights. Employees with high WFH feasibility level are defined as those reporting a value of the WFH feasibility index above the sample median (52.2) 
households or in the South of Italy, those having a temporary or other atypical job contracts, and those working in the private sectors.

Finally, it can be noted that employees with high WFH feasibility levels are more often female, older, high educated, as well as among those living in metropolitan cities (Table 1). Interestingly, a higher level of WFH feasibility does not therefore imply a greater labour income on average as, for instance, employees living in metropolitan areas or female ones in particular are not the groups reporting highest income levels.

Figure 1 brings out that economic activity sectors being characterised by greater shares of employees with high WFH feasibility are finance and insurance, information and communications, professional services, other business services (e.g. car renting, travel agencies, employment agencies), and public administration. Figure 1 also highlights that employees working in sectors with high WFH feasibility receive, on average, a greater annual labour income than the others ( $€ 27,300$ vs. $€ 24,700)$. Looking at differences between sectors, employees with high feasibility levels receive this 'wage premium' in 13 out of 21 sectors, and sometimes - in B and E sectors - the wage premium is remarkable. At the opposite, employees with high WFH feasibility receive a lower labour income than the others especially in hotel and restaurants and personal services (i.e. R-U sectors).

As for potential differences across the labour income distribution, Fig. 2 clearly shows that the wage gap between employees with high and low WFH feasibility is increasing along the distribution and reaches highest values in the last two decile groups, as well as the same incidence of high WFH feasibility among employees.

\subsection{Kolmogorov-Smirnov test}

In Fig. 3, we plot the kernel estimates of the labour income density for both groups. It can be noted that the income distribution for employees with high WFH feasibility is clearly shifted to the right with respect to that of employees with low WFH feasibility.

Researchers, not only in the economic literature, are often interested in evaluating the homogeneity of distributions across different samples and the KolmogorovSmirnov (K-S) statistic, which is obtained as the largest discrepancy of the empirical distribution functions by these samples, is probably the most used approach (Lehmann and Romano 2005; Leonida et al. 2020; Otsu and Taniguchi 2020). Therefore, in order to preliminarily test any difference in all moments between the two distributions, we develop the non-parametric K-S test based on the concept of stochastic dominance. ${ }^{8}$

Results of the K-S test for the first order stochastic dominance shown in Table 2 confirm that the annual gross labour incomes of employees with high WFH feasibility stochastically dominate, at the $1 \%$ level of significance, those reported by employees performing professions with low WFH feasibility.

\footnotetext{
${ }^{8}$ The notion of first-order stochastic dominance can establish a ranking for compared distributions. Let $F$ and $G$ denote the cumulative distribution functions of wages for two groups, e.g. workers with high and low WFH feasibility. First-order stochastic dominance of $F$ relative to $G$ is defined as: $F(z)-G(z) \leq 0$ uniformly in $z \in R$, with strict inequality for some $z$. To test whether there are statistically robust differences between distributions, we adopt both the one-sided and two-sided K-S tests. The two-sided test $\left(\mathrm{KS}_{2}\right)$ permits one to determine whether both distributions are identical, while the one-sided test $\left(\mathrm{KS}_{1}\right)$ determines whether one distribution dominates the other. Thus, to state that $F$ stochastically dominates $G$, a rejection of the null hypothesis for the two-sided test is required, while the null for the one-sided test cannot be rejected.
} 


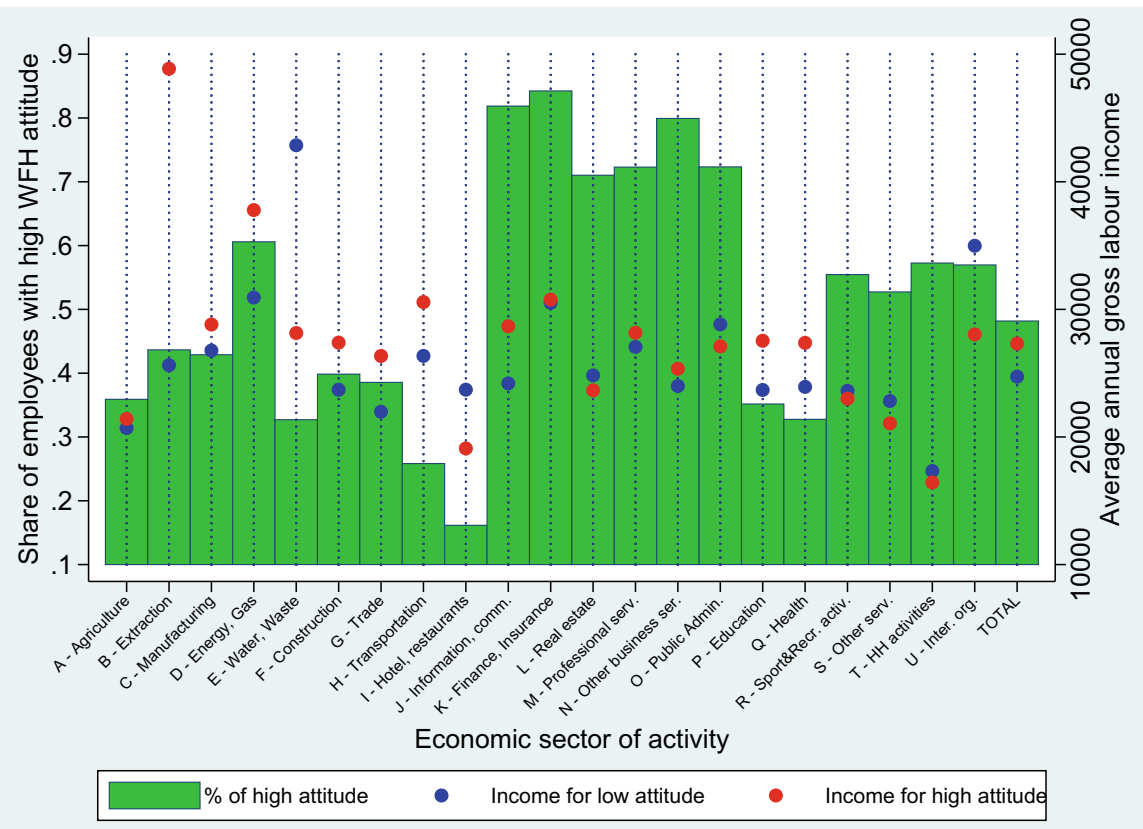

Fig. 1 Incidence of high WFH feasibility and average labour income by activity sector. Notes: Descriptive statistics are computed with individual sample weights. Employees with high WFH feasibility level are defined as those reporting a value of the WFH feasibility index above the relevant sample median

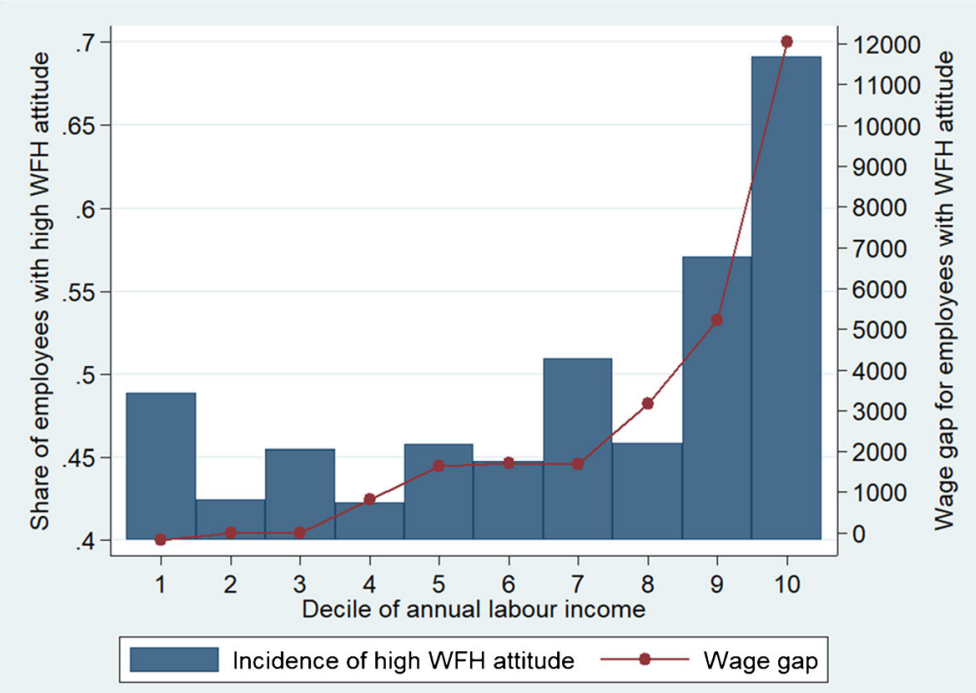

Fig. 2 Incidence of high WFH feasibility and wage gap in favour of employees with high feasibility levels by decile of annual income. Notes: Descriptive statistics are computed with individual sample weights. Employees with high WFH feasibility level are defined as those reporting a value of the WFH feasibility index above the relevant sample median 


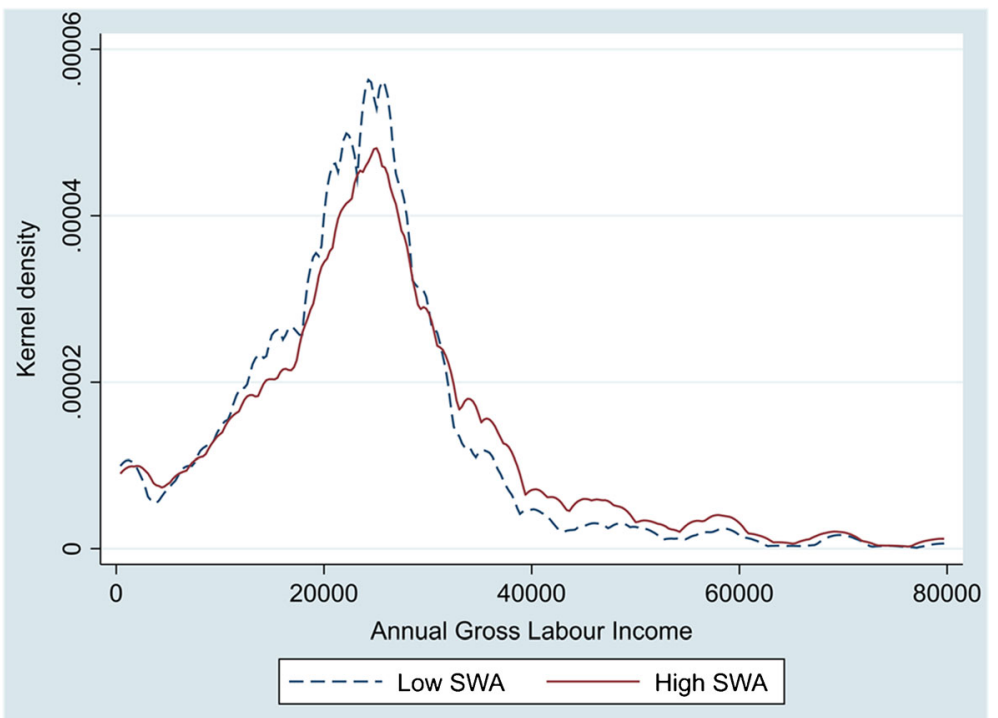

Fig. 3 Labour income distribution by level of WFH feasibility. Notes: Descriptive statistics are computed with individual sample weights. Employees with high WFH feasibility level are defined as those reporting a value of the WFH feasibility index above the relevant sample median

\section{Econometric methods}

The merge of ICP and INAPP-PLUS data provides a representative snapshot on the levels of WFH feasibility of all professions in the Italian labour market and their relationship with labour incomes in 2018. However, restrictive measures introduced to cope with the recent COVID-19 pandemic forced many firms and institutions to innovate their work organisation, workplaces (e.g. offices or plants), and procedures to be able continuing the goods production or services provision. The extra-ordinary situation and massive limitations to personal mobility led, in particular, to entitle employees in both the private and public sector to WFH, despite this way of working is not popular nor precisely regulated in the country (see Sect. 2.3). As a consequence, this event is expected to determine some long-lasting effects (or at least in the medium term) on the actual levels of WFH feasibility of a relevant number of professions.

The aim of this paper consists of estimating the potential influences related to a (persistent) positive shift in the WFH feasibility of employees on the overall labour income distribution. To this end, in the econometric analysis, we adopted the

Table 2 Kolmogorov-Smirnov test for comparison between employees with high and low WFH feasibility

\begin{tabular}{llll}
\hline & Combined & Low WFH feasibility & High WFH feasibility \\
\hline $\mathrm{KS}_{2}$ & $0.0976(0.000)$ & & \\
$\mathrm{KS}_{1}$ & & $0.0976(0.000)$ & $-0.0059(0.7333)$ \\
\hline
\end{tabular}

Note: $p$ values in parentheses. Descriptive statistics are computed with individual sample weights. Employees with high WFH feasibility level are defined as those reporting a value of the WFH feasibility index above the relevant sample median 
unconditional quantile regression method as proposed by Firpo et al. (2009). With respect to the (conventional) quantile regression method developed by Koenker and Bassett (1978), this methodology has the merit to estimate the effects on an outcome variable distribution which is not conditioned by the set of covariates included in the model (Fortin et al. 2011). It allows, for instance, to directly compare results of income differences between groups of employees at different points of the distribution without imposing a path dependence in the gap estimation at different quantiles (Gaeta et al. 2018). Also, the method proposed by Firpo et al. (2009) allows to include additional covariates in the model without altering the interpretation of estimated coefficients on the distributional statistic, such as the mean or a quantile. This study does not represent the first application of this methodology with Italian data (see, amongst others, Gaeta et al. 2018; Regoli et al. 2019; Gallo and Pagliacci 2020), but the first one analysing in this way the relationship between WFH and wage inequality.

The unconditional quantile regression method involves the calculation of the recentred influence function (RIF) which is defined as

$$
\operatorname{RIF}(y ; v, F)=v(F)+\operatorname{IF}(y ; v, F)=v(F)+\lim _{t \downarrow 0} \frac{v\left((1-t) F+t \Delta_{y}\right)-v(F)}{t}
$$

where $F$ is the distribution function of the outcome variable $y$ (i.e. the gross labour income), $v(F)$ denotes a distributional statistic, and the $\operatorname{IF}(y ; v, F)$ is the influence function initially introduced by Hampel (1974). According to Firpo et al. (2009), once the values of $\operatorname{RIF}(y ; v, F)$ are computed for all observations, the effects of a marginal change in the distribution of the variable of interest (i.e. WFH feasibility) on the distributional statistic $v(F)$ can be correctly calculated through a simple OLS estimation. Following Choe and Van Kerm (2018), we both label this measure as 'unconditional effect' (UE) and determine a marginal change in the distribution of the WFH feasibility swapping a 10 percentage points share of employees from one feasibility level to the other one. In other words, considering the baseline feasibility levels across Italian employees as the counterfactual scenario, we estimate the UE of a WFH feasibility increase on labour income inequality moving toward a distribution composed of 10 percentage point less employees with a low level of WFH feasibility and 10 percentage point more employees with a high feasibility level. In this 'shares swap' scenario, within-groups income distributions remain constant.

The unconditional quantile regression method also allows for taking into account demographic and economic characteristics which may differ across employees, leading to potential biases on policy influences. We then regressed RIFs on the variable of interest and a vector $Z$ of relevant covariates including demographic characteristics regarding the individual and her household (i.e. gender, age group, education level, migration status, marital status, household size, presence of minors, municipality size, and macro-region of residence) and job characteristics (i.e. job contract, public servant, and activity sector dummies). More details on variables included in the model are provided in Appendix Table 7. The resulting effect on distributional statistics is labelled in this case as 'unconditional partial effect' (UPE) (Firpo et al. 2009; Choe and Van Kerm 2018), but it is also named 'policy effect' or 'counterfactual effect' in the literature (Rothe 2010; Chernozhukov et al. 2013; Gallo and Pagliacci 2020). The 
main difference between UEs and UPEs relies on the fact that in the UEs calculation the WFH feasibility shift determines a consequent change in covariates in the vector $Z$ according to the joint income distribution, whereas in the UPEs estimation these covariates are explicitly kept constant.

In this study, we estimate influences of a positive shift in the WFH feasibility on gross labour income distribution focusing on the following distributional statistics: the mean, the Gini index, and the nine deciles. ${ }^{9}$ Sample values of first two statistics are reported in Sect. 3.2, while values of the nine deciles are presented in Appendix Fig 7. Differently from the common choice to drop female employees to minimise selection issues, we decided not to restrict the sample to males only but to show separated results by males and females. To further explore the heterogeneous influences of an overall increase of WFH feasibility along labour income distribution, we also report main results distinguishing by age group and the attained education level (i.e. graduated rather than non-graduated). Finally, taking advantage by data provided by the Italian Civil Protection Department (2020) on the extent of COVID-19 infection at provincial (NUTS-3) level, we verify whether effects related to a WFH feasibility shift over time are expected to be greater in those areas more affected by the pandemic (i.e. overall COVID-19 cases represent more than $3.2 \%$ of total population).

As a sensitivity analysis, to control for the occupation skill heterogeneity among employees, we estimated our main results using a set of covariates including skill level dummies. In addition, given the potential endogeneity of job characteristics on the dependent variable, we also replicated UPE estimates adopting a set of covariates excluding these characteristics. As further robustness checks, we observed effects on different inequality indicators and controlled for potential endogeneity and selection issues related to the WFH feasibility. Results of all these checks are provided in Sect. 6 and overall confirm the robustness of our main considerations.

\section{Results}

\subsection{Influences on labour income inequality}

Table 3 highlights that a positive shift in WFH feasibility levels would significantly influence the labour income distribution and inequality. Specifically, RIF regression results suggest that swapping a 10 percentage points share of employees from the low feasibility level to the high one would be associated to an increase of both the mean labour income up to $€ 259$ (we refer to that as 'premium') and the Gini index for about 0.004 points. Considering that the mean labour income in our sample is equal to about $€ 26,000$ (see Table 1), a slight growth of WFH feasibility would be therefore linked to a $1 \%$ increase on the mean labour income. Taking advantage from the intrinsic functioning of the RIF regressions methodology, this estimated influence on the mean labour income (and Gini index) may be extended according to the assumption adopted on the employees shares swap. This means that, for instance, if the share of employees moving from low to high feasibility level is 20 (or 50) percentage points, then the

\footnotetext{
${ }^{9}$ For the sake of brevity, formulas to calculate the RIFs for the mean, the Gini index, and the quantiles are not replicated here, but they can be easily found in Choe and Van Kerm (2018).
} 
increase on the mean labour income and Gini index will be $2 \%$ and 0.008 (or $5 \%$ and 0.02), respectively. As expected, UPE estimates (i.e. thus ones based on a model specification including relevant covariates) present reduced magnitudes, but effects remain overall positive and significant on the Gini index.

Disaggregating by employees' characteristics, we find that the wage premium related to an increase of WFH feasibility mainly regards male - further enlarging the gender pay gap (see Table 1) — graduated, younger, and older employees. To this end, our results are in line with Goldin (2014) who reports that the gender wage gap may be also due to lack of flexibility in work arrangements, particularly in financial and business services, which we find being sectors with greater incidences of high WFH feasibility (Fig. 1). Also, according to results in Table 3, a positive shift in WFH feasibility levels among Italian employees would increase the Gini index especially among female, younger, older, and graduated employees. As for the influences on incomes of a change of WFH feasibility by education level, however, when controlling for relevant covariates (i.e. UPE estimates), any significant difference appears among the two groups of employees.

Looking at the WFH feasibility influences along the labour income distribution (topleft panel of Fig. 4), 10 percentage points swap of employees from low to high WFH feasibility appears to reward more high-paid employees, while it has no significant effects (or even negative when looking at UPE estimates) in the left-side of the distribution. In particular, the highest 'wage premium' would be reached at the 8th decile where it amounts to about $€ 500$, thus leading to a $1.7 \%$ increase with respect to its baseline value (Appendix Fig 8).

Top-right panel of Fig. 4 points out that the wage premium deriving from a growth of WFH feasibility levels would be mainly in favour of male employees, whereas that

Table 3 Unconditional effects of a positive shift in the WFH feasibility on the mean and Gini index

\begin{tabular}{|c|c|c|c|c|}
\hline \multirow[t]{2}{*}{ Group of employees } & \multicolumn{2}{|l|}{ Mean value } & \multicolumn{2}{|l|}{ Gini index } \\
\hline & UE & UPE & UE & UPE \\
\hline Total sample & $258.86^{* * *}$ & 97.98 & $0.004 * *$ & $0.004 * *$ \\
\hline Male & $473.03 * * *$ & $233.81 * *$ & 0.004 & 0.004 \\
\hline Female & $111.02 * *$ & -33.66 & $0.002 * *$ & 0.001 \\
\hline Aged 25-35 & $375.75 * * *$ & $270.60^{*}$ & 0.005 & $0.008^{*}$ \\
\hline Aged 36-50 & 24.07 & -82.64 & 0.001 & 0.001 \\
\hline Aged 51-64 & $496.39 * * *$ & $250.78^{* *}$ & $0.007 * * *$ & $0.005^{*}$ \\
\hline Non-graduated & 131.15 & $153.17^{*}$ & 0.003 & 0.003 \\
\hline Graduated & $410.91 * * *$ & $167.95^{*}$ & $0.005 * * *$ & 0.000 \\
\hline
\end{tabular}

Notes: Standard errors are clustered by NUTS-3 region and estimates are computed with individual sample weights. The table presents coefficients of the variable of interest (i.e. high WFH feasibility) only. Complete estimates for the pooled sample are provided in Appendix Table 9. Employees with high WFH feasibility level are defined as those reporting a value of the WFH feasibility index above the relevant sample median. UE estimates are based on a model specification that only includes the variable of interest, while for UPE estimates, additional covariates are included in the model (see Sect. 4)

$* p<0.1 ; * * p<0.05 ; * * * p<0.01$ 

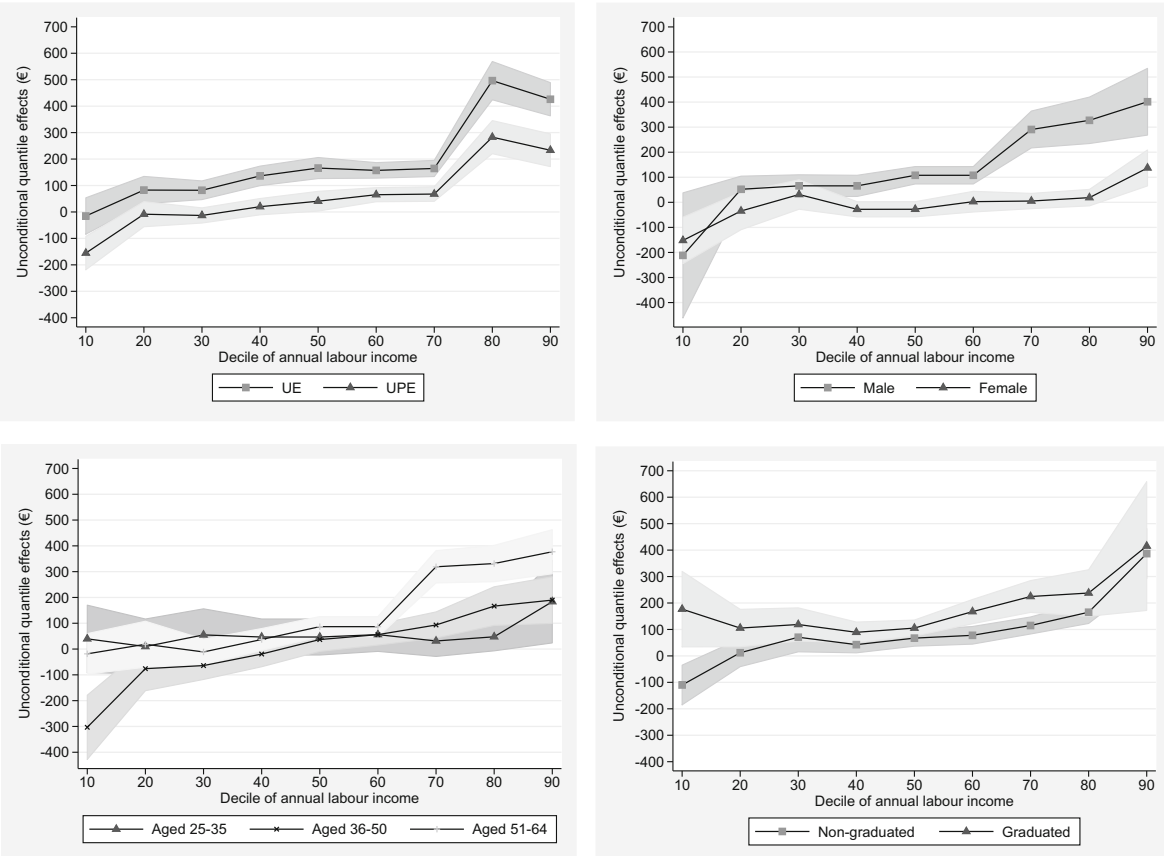

Fig. 4 Unconditional effects of a positive shift in the WFH feasibility along labour income distribution. Notes: Standard errors are clustered by NUTS-3 region and estimates are computed with individual sample weights. Shadowed area reports confidence intervals at $90 \%$ level. The figures present coefficients of the variable of interest (i.e. high WFH feasibility) only. Employees with high WFH feasibility level are defined as those reporting a value of the WFH feasibility index above the relevant sample median. UE estimates are based on a model specification that only includes the variable of interest, while for UPE estimates additional covariates are included in the model (see Sect. 4). Estimates by employees' characteristics refer to the UPE specification. Complete estimates for the pooled sample are provided in Appendices 1.4 and 1.5

would represent a penalty for female ones except for those in last decile group. (Note that the latter would receive a lower premium than males though.) A positive shift in WFH feasibility levels among employees aged 25-35 would have an overall stable but statistically insignificant effect along their whole distribution (bottom-left panel of Fig. 4). At the opposite, swapping employees with low WFH feasibility levels with others with high feasibility levels would produce unequal influences along labour income distribution of older employees. In particular, employees aged 36-50 would report a wage penalty in the first three deciles and a relevant premium from the sixth decile onwards, while employees aged 51 or more would receive the highest rewards in the right-side of income distribution.

The bottom-right panel of Fig. 4 points out a similar distributional pattern of UPEs among non-graduated and graduated employees related to a positive shift in WFH feasibility levels. This event would indeed be associated in both groups with a growth of labour income levels which is overall increasing along the distribution. Nevertheless, estimated UPE among graduated employees are slightly greater with respect to the ones reported by the other group (especially in the sixth and seventh deciles), in line with the SBTC explanation (amongst others, see Van Reenen 1997; Berman et al. 1998; Autor et al. 1998, 2002, 2003; Acemoglu 2002). In fact, technological innovations are not 
neutral and tend to increase the productivity of skilled labour, usually identified through a high level of education, compared with unskilled work, thus causing an increase in wage inequality levels. Our results show that the technological change would occur to determine the hypothesised shift in WFH feasibility levels is likely to strengthen existing wage inequalities between high and low educated employees. In this context, the existing relationship between new technologies and high paid jobs is a key factor of wage polarisation, which in turn is fundamental to better understand and forecast possible long run consequences of the COVID-19 outbreak such as a persistent change in the ways of working.

\subsection{Estimates by incidence of COVID-19 infection}

In this section, we present some pieces of evidence on how a positive shift in the WFH feasibility levels would influence the labour income distribution characterising local labour markets. Specifically, under the assumption that the structure of professions and their WFH feasibility remained unchanged from 2018 to 2020, we are interested to explore if this 'forced innovation' (potentially) regarding 10 percentage points of employees with a low feasibility level would affect more labour incomes in provinces which reported the highest numbers of COVID-19 cases from 24 February to 5 May 2020 (Civil Protection Department 2020). We distinguish between two areas (i.e. less/more COVID-19-infected area) according to the local infection incidence, thus the incidence of COVID-19 cases on total population at provincial level. We consider as 'more COVID-19-infected area' those provinces reporting an infection incidence over the sample median (i.e. 3.2\%o). Appendix Fig 9 provides COVID-19 infection incidences by province and overall shows that areas in the North of Italy are those more affected by the novel coronavirus, with the only exception of Marche (which belongs to the Centre of Italy). Given the adopted definition, our sample of employees is almost equally divided in the two areas (i.e. $52 \%$ of the sample lives in less COVID-19infected provinces and $48 \%$ in more infected ones). No significant differences are revealed between these two groups of employees as regards our variable of interest (more details upon request), since they report similar values for both the average WFH feasibility level (52.2 in less-infected areas and 52.5 in more-infected areas) and the share of employees with a high feasibility level (48.7 and 47.6, respectively).

Table 4 highlights that employees living in more COVID-19-infected areas report a slightly higher labour income on average and lower levels of income inequality (in terms of Gini index) with respect to the ones living in less-affected areas.

As for the UE and UPE estimates on the mean value of labour income, results show that the effects related to a positive shift in the WFH feasibility would be greater and more significant among employees being resident in provinces more affected by the pandemic (i.e. the Northern and more developed ones). The same consideration occurs when referring to unconditional effects on the Gini index of labour income, because they appear insignificant among employees living in areas reported a lower incidence of COVID-19 infection.

Results illustrated in Fig. 5 overall confirms that employees in more COVID-19infected area would benefit more from a marginal improvement in WFH feasibility levels of professions. The increase in income levels associated to a positive shift in feasibility levels would be indeed greater for this group of employees in both the central 
Table 4 Unconditional effects of a positive shift in the WFH feasibility by COVID-19 infection incidence

\begin{tabular}{|c|c|c|c|c|c|}
\hline \multirow[t]{2}{*}{ Group of employees } & \multirow[t]{2}{*}{ Statistic } & \multicolumn{2}{|l|}{ Mean value } & \multicolumn{2}{|c|}{ Gini index } \\
\hline & & UE & UPE & UE & UPE \\
\hline \multirow[t]{2}{*}{ Less COVID-19-infected area } & Baseline value & 25,624 & & 0.297 & \\
\hline & Unconditional effect & $193.36^{*}$ & 46.50 & 0.003 & 0.004 \\
\hline \multirow[t]{2}{*}{ More COVID-19-infected area } & Baseline value & 26,356 & & 0.262 & \\
\hline & Unconditional effect & $330.43 * * *$ & $137.19 * *$ & $0.005^{*}$ & $0.003^{*}$ \\
\hline
\end{tabular}

Notes: Standard errors are clustered by NUTS-3 region and estimates are computed with individual sample weights. Unconditional effects refer to the variable of interest (i.e. high WFH feasibility) only. Employees with high WFH feasibility level are defined as those reporting a value of the WFH feasibility index above the relevant sample median. UE estimates are based on a model specification that only includes the variable of interest, while for UPE estimates, additional covariates are included in the model (see Sect. 4)

$* p<0.1 ; * * p<0.05 ; * * * p<0.01$

part (fourth and fifth deciles) and right side of distribution (seventh and eighth deciles). (The latter is less significant when we look at UPE estimates.).

This is an interesting and important evidence as these territories actually needed for this kind of policy, although its potential influence remains unequal along the labour income distribution as it would be more in favour of high-paid employees.

\subsection{Estimates by single item of the WFH feasibility index}

Our analysis relies on the multidimensional index recently proposed by Barbieri et al. (2020), which try to assess the WFH feasibility of each profession performed in the Italian labour market looking at seven different items or dimensions. For each of the seven items listed in Sect. 3.1, a standardised index with a 0-100 range is computed. Except for the item 'working with computers', the other six dimensions has to be
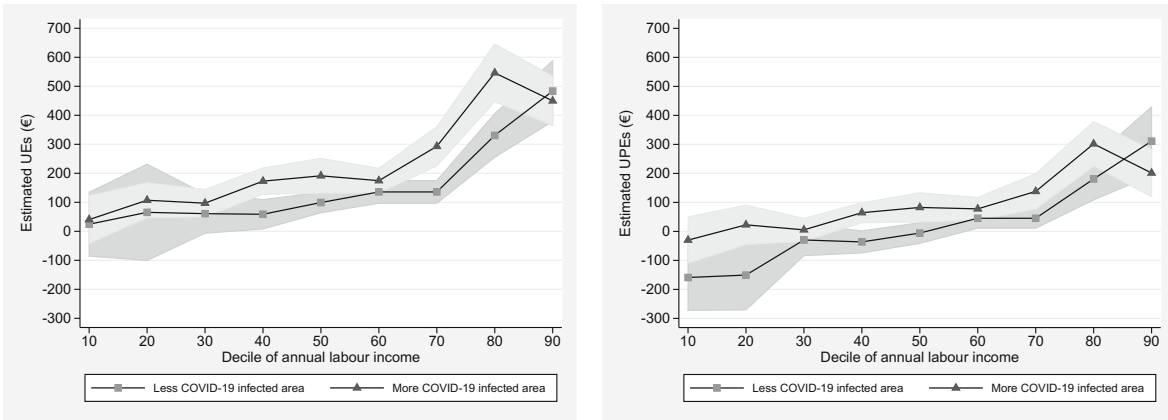

Fig. 5 Unconditional effects of a positive shift in the WFH feasibility along labour income distribution by COVID-19 infection incidence. Notes: Standard errors are clustered by NUTS-3 region and estimates are computed with individual sample weights. Shadowed area reports confidence intervals at $90 \%$ level. The figures present coefficients of the variable of interest (i.e. high WFH feasibility) only. Employees with high WFH feasibility level are defined as those reporting a value of the WFH feasibility index above the relevant sample median. UE estimates (in the left panel) are based on a model specification that only includes the variable of interest, while for UPE estimates (in the right panel) additional covariates are included in the model (see Sect. 4) 
considered reversely. The 'reverse indexes', used to obtain the multidimensional index, are then calculated through a raw difference between 100 and the initial indexes.

Using the WFH feasibility index as variable of interest allows us to assess influences that may emerge from a marginal shift in its distribution among employees on labour income levels without assuming any specific technological change. For instance, considering the adopted multidimensional index, an increase in the WFH feasibility levels (i.e. a swap of employees having a low WFH feasibility level with other employees having a high one) may be gained reducing the performance of physical activities, encouraging the use of computers or decreasing the need of face-to-face discussions at work. However, it may appear of some interest better understanding how a marginal change on single items composing the WFH feasibility index would eventually influence the labour income distribution.

To provide further insights on the potential effect of a change in the WFH feasibility of professions on the wage distribution, we therefore replicate in this section our main analysis using as variable of interest the indexes referring to single items of the adopted multidimensional index. Of course, reverse indexes are considered for those items acting reversely on the total index, so that if an employee presents a high value of the index regarding, for instance, 'spending time standing' then it actually means that she spends a small amount of time standing to do her job. Also in this case, variables of interest are defined as dummy variables taking value 1 if the employee reports a value of the specific index over the sample median, and 0 otherwise. The seven, say, 'threshold values' are reported in Table 5, together with the one used for our main variable (i.e. WFH feasibility index). The highest threshold values are reported by indexes referring to 'performing physical activities' and 'manoeuvring vehicles or machines', because only few employees need these activities to perform tasks related to their profession. At the opposite, the lowest sample median is the one associated to the 'face-to-face discussion' index as most of employees consider this activity important in their profession.

Table 5 shows UE and UPE estimates by item of the WFH feasibility index under the hypothesis of moving toward a distribution composed of 10 percentage point less employees with low values of a specific index and 10 percentage point more employees with high values of the same index. As regard to the 'working with computers' item, this change is interpreted as an increase in the number of employees using a computer to make their occupation. As for the other items, because they act reversely in the adopted multidimensional index, this change has to be interpreted as a decrease in the number of employees for which a specific activity (e.g. manoeuvring vehicles or machines) or profession feature (e.g. dealing with customers and public, physical proximity) is important to perform their job. ${ }^{10}$

\footnotetext{
${ }^{10}$ Some of the single indexes on which the WFH feasibility index is based, in their initial version (i.e. before being reversed) and in a $0-100$ range, report value 0 for a number of employees. This happens when a specific dimension/activity is totally unrelated or necessary to develop a profession. This phenomenon mainly occurs in the index regarding 'performing physical activities' (value equals to 0 for 455 observations) and 'manoeuvring vehicles or machines' (0 for 2594 observations). Because these 0 values may represent a potential issue for estimates referring to the two indexes, we also replicated the same analysis excluding employees who report this peculiarity. Results of this sensitivity analysis (Appendix 1.6) overall confirm the ones presented in Table 5, except for the fact that a reduction of employees for whom manoeuvring vehicles or machines is important does not significantly increase anymore the Gini index of labour income.
} 
Table 5 Unconditional effects on mean value and Gini index by item of the WFH feasibility index

\begin{tabular}{|c|c|c|c|c|c|}
\hline \multirow[t]{2}{*}{ Item of the multidimensional index } & \multirow[t]{2}{*}{ Threshold value } & \multicolumn{2}{|l|}{ Mean value } & \multicolumn{2}{|l|}{ Gini index } \\
\hline & & UE & UPE & UE & UPE \\
\hline Performing physical activities ${ }^{\mathrm{a}}$ & 82.9 & $388.07 * * *$ & $211.61 * * *$ & 0.000 & 0.002 \\
\hline Working with computers & 49.5 & $507.49 * * *$ & $249.27 * * *$ & 0.001 & 0.002 \\
\hline $\begin{array}{l}\text { Maneuvering vehicles } \\
\text { or machines }\end{array}$ & 96.0 & 5.48 & 128.62 & 0.002 & $0.004 * *$ \\
\hline Face-to-face discussion ${ }^{\mathrm{a}}$ & 22.0 & $-274.30 * * *$ & -171.03 & 0.002 & 0.001 \\
\hline $\begin{array}{l}\text { Dealing with customers } \\
\text { and public }\end{array}$ & 46.0 & $-243.08 * * *$ & $-205.62 * * *$ & -0.002 & -0.003 \\
\hline Physical proximity ${ }^{\mathrm{a}}$ & 63.8 & $-394.20 * * *$ & $-208.31 * * *$ & $-0.005 * * *$ & $-0.005^{* * *}$ \\
\hline Spending time standing ${ }^{a}$ & 47.0 & $469.31 * * *$ & $292.61 * * *$ & 0.002 & $0.003 * *$ \\
\hline WFH feasibility (total) & 52.2 & $258.86^{* * *}$ & 97.98 & $0.004 * *$ & $0.004 * *$ \\
\hline
\end{tabular}

Notes: Standard errors are clustered by NUTS-3 region and estimates are computed with individual sample weights. Unconditional effects refer to the variable of interest (i.e. high index value) only. Employees with high index value are defined, for each item, as those reporting a value of the single index over the threshold value illustrated in the table (i.e. the sample median). UE estimates are based on a model specification that only includes the variable of interest, while for UPE estimates, additional covariates are included in the model (see Sect. 4)

$* p<0.1 ; * * p<0.05 ; * * * p<0.01$

a The index referring to the specific item is reversely considered

Table 5 highlights that not all items composing the WFH feasibility index goes in the same direction revealed by the total (multidimensional) index in terms of unconditional effects on the mean value of labour income. In fact, only an increase in the employees' feasibility of working with computers, a reduction in their feasibility of performing physical activities, or a decline in the importance of spending time standing would be associated to positive and significant influences on the mean income. The highest 'wage premium' would come from a potential growth of employees working with computers confirms, once again, the role of technological change in wage levels and inequality highlighted in many OECD countries since the 1980s (Krueger 1993; Freeman and Katz 1995; Gottschalk and Smeeding 1997; Autor et al. 1998; Berman et al. 1998; Acemoglu 2003).

At the opposite, reducing the physical proximity to other colleagues in the workplace for a share of employees, as well as the need in performing their profession to deal with customers and public or to make face-to-face discussion, would significantly be related to an overall decrease of income levels. The main reason for this evidence is related to the fact that these activities/features of professions are positively correlated to the labour income, ${ }^{11}$ even when controlling for relevant covariates (UPEs remain statistically

\footnotetext{
${ }^{11}$ As regards the physical proximity among colleagues at the workplace, additional elaborations of the authors show that employees reporting high levels of physical proximity present an annual gross labour income about $€ 4000$ greater on average than the others. This peculiarity of the Italian labour market-Mongey et al. (2020) show the opposite for the USA - is related to the fact that high physical-proximity employees tend to be paid much more than low physical-proximity ones in Health, Public Administration, and Trade sectors. Also, 24\% of high physical-proximity employees work in the highly profitable Manufacturing sector, while $30 \%$ of high physical-proximity employees work in the much less profitable Education and Trade sectors (see Appendix 1.2 for average income levels by sector). More details are available upon request to the authors.
} 
significant for the item 'dealing with customers and public' and the one referring to physical proximity). Interestingly, the latter evidence on professions performed in Italy appears in contrast with results reported by Mongey et al. (2020) for the US labour market, which show that high physical-proximity workers tend to have lower incomes and their potential reduction would lead to an increase of the average income.

A change in feasibility levels regarding manoeuvring vehicles or machines would instead have no significant effect on the mean value of labour income. As for the effects on the Gini index of labour income, results by single item are overall in line with those on the average income but with a lower statistical significance. Looking at UPE estimates, the effects on the Gini index are significant at $5 \%$ level only for three items: manoeuvring vehicles or machines, physical proximity, and spending time standing. More specifically, a reduction of physical proximity among employees would be associated with a decreasing income inequality, whereas a reduction of employees who spend a lot of time standing or manoeuvring vehicles or machines would increase the Gini index of labour income.

Figure 6 helps to better explain the role of a change in single items composing the adopted WFH feasibility index on the labour income inequality illustrating unconditional effects by income decile. Most of times present indeed insignificant effects on the Gini index, and thus on the income inequality, probably because estimated influences related to a marginal 'low-to-high' change of employees are stable along the labour income distribution, except for the last two deciles. At the opposite, the negative effect of a reduction of physical proximity among employees would be clearly increasing (in absolute terms) along the distribution, so that high-paid employees would 'pay' more this kind of change in professions.

Figure 6 also supports to understand why a reduction of employees manoeuvring vehicles or machines would have no effect on the mean value of labour income but increase its inequality levels. In fact, the employees' swapping would have a negative effect on the first two deciles of income distribution, then its effects appear insignificant in the central part of distribution (i.e. third fifth deciles), and finally it would influence positively and increasingly incomes in the right side of distribution.

\section{Robustness checks}

In this section, we briefly summarise several robustness checks of the main results presented in the paper, concerning sample restrictions, the specification of our variables of interest, the adoption of different income inequality indexes, the inclusion of endogenous or additional covariates in the regressions, the use of sample weights, and potential selection issues related to the WFH feasibility of professions. Results of robustness checks performed are illustrated in Appendix 2 and more details are available upon request to the authors.

First, as our analysis is based on a definition of labour income which is annual referred, we then need to verify that our results might be biased by the presence of parttime and temporary employees in the sample. So, in this robustness check, we drop from the sample all employees having these employment contracts. Results by including only full-time open-ended employees (9812 observations) are presented in Appendix Table 13 and the left panel of Appendix Fig 10 and strongly corroborate our main 

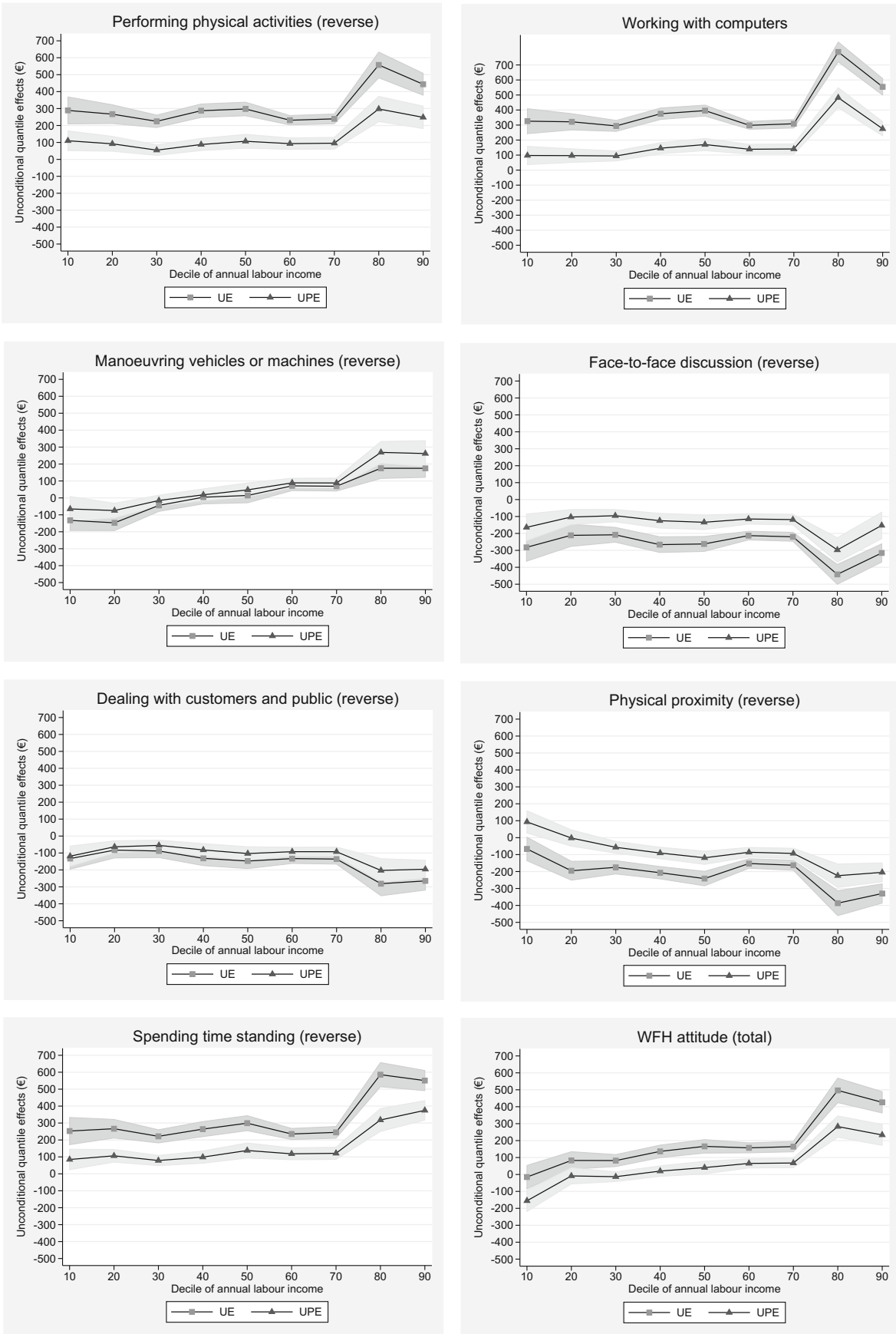

Fig. 6 Unconditional effects along income distribution by item of the WFH feasibility index. Notes: Standard errors are clustered by NUTS-3 region and estimates are computed with individual sample weights. Shadowed area reports confidence intervals at $90 \%$ level. The figures present coefficients of the variable of interest (i.e. high feasibility) only. Employees with high feasibility level are defined, for each item, as those reporting a value of the single index over the sample median. UE estimates are based on a model specification that only includes the variable of interest, while for UPE estimates, additional covariates are included in the model (see Sect. 4) 
conclusions. Similarly, to be sure the adopted sample restriction strategy (detailed described in Sect. 3) did not affect our results, we made a sensitivity analysis including in the sample self-employed individuals aged 25-64 years old and with no missing values in relevant variables. Also here, estimation results based on a sample of employed and self-employed (17,899 observations in total) and presented in Appendix Table 14 and the right panel of Appendix Fig 10 seem to overall confirm the robustness of our main results.

Second, as anticipated in Sect. 3.1, we developed several robustness checks on the specification of our variable of interest. Specifically, we replaced the dummy specification of the WFH feasibility variable with a continuous one, as well as with a quintile, quartile, or tertile groups specification. Also, keeping constant the dummy specification, we changed the definition of the WFH feasibility variable making it take value 1 over the sample mean (rather than the median) or $60 \%$ of the sample mean. As for the continuous variable of interest (i.e. WFH feasibility index), in line with the methodology proposed by Firpo et al. (2009), unconditional effects are estimated assuming a one-unit increase on the average value of the same variable among employees. In other words, results of this sensitivity analysis provide potential influences on labour income levels and inequality related to an increase of the WFH feasibility index of all professions in the Italian labour market, so that its mean value in our sample moves from 52.4 to 53.4. As for the variables of interest with levels specification, UE and UPE estimates are still obtained through a 'employees shares swap', but in this case, replacing employees in the first level (i.e. the first quintile/quartile/tertile group) with employees in another one. For instance, a shares swap scenario may be represented by a distribution composed of 10 percentage point less employees in the first quintile group of WFH feasibility and 10 percentage point more employees in the fourth quintile group.

Appendices 2.3 and 2.11 report estimation results for the continuous specification of our variable of interest, while Appendix Fig 12 shows UPE estimates for all the other specifications attempted (in comparison with those attained through the base specification in panel A). When the counterfactual scenario of a WFH feasibility increase is based on a positive shift of the WFH feasibility index (in its continuous specification), unconditional effects on the mean and Gini index of labour income are pretty similar to those reported in Tables 3 and 4 but less significant on the income inequality and when relevant covariates are included in the model (Appendix Table 15). However, Appendix Fig 11 confirms that an increase of the average WFH feasibility would be related to a 'wage premium' which is greater among high-paid, male, and aged 51-64 employees (differences in the premium between non-graduated and graduated employees are instead less sharp). Results illustrated in Appendix Fig 12 overall validate our main conclusions too, showing that a swap of employees with low values of the WFH feasibility index and others reporting high values would increase income levels especially in the right side of the labour income distribution. Since single items composing the adopted multidimensional index may be used as continuous variables, as a further sensitivity analysis, we replicated estimates provided in Table 5 using as variable of interest the single indexes in their standard (continuous) specification. Appendix Table 16 shows that our main results hold also when considering single items as continuous variables.

Third, we run RIF estimates on two different income inequality indexes with respect to the one we adopted (i.e. the Gini index): the mean log deviation and the Atkinson 
index with $e=1$. Results of these tests, presented in Appendix Table 17 for the pooled sample and by group of employees, overall confirm the robustness of our main conclusions. The only exception regards the fact that a positive shift of WFH feasibility seems not to influence anymore income inequality indexes in areas more affected by the recent COVID-19 pandemic (despite influences are clearly increasing along the labour income distribution, see Fig. 5).

Fourth, we tried to change the set of covariates adopted for UPE estimates to assess two different issues: potential endogeneity of covariates related to job characteristics and skill heterogeneity among employees. As for the potential endogeneity of job characteristics on the dependent variable, we define a new vector of covariates (UPE2) which includes only demographic characteristics regarding the individual and her household. Estimates based on the UPE2 specification, reported in Appendix Table 18 for the effects on mean value and inequality indexes of labour income and in both Appendices Table 19 and Fig 13 for the effects along the income distribution, show that our main results hold. As for the skill heterogeneity among employees, we enlarge the set of covariates used for UPE estimates including other three (probably endogenous) variables to solve this issue. Specifically, we add the occupation skill level of employees to control for skill heterogeneity as suggested by Picchio and Mussida (2011) and Leonida et al. (2020). The occupation skill level is included through a set of dummy variables representing different levels of the ISCO classification of occupations. In particular, we define as: 'medium skill level', employees in the fourth ISCO level (i.e. clerical support workers); 'high skill level', employees in the third one (i.e. technicians and associate professionals); and 'very high skill level', employees in the first two ISCO levels (i.e. managers and professionals). The reference category is 'low skill level'. We label estimates based on this model specification as UPE3 and we present them for the total sample in Appendices 2.6 and 2.8. Outcomes of these robustness checks overall confirm that our main results hold even considering these additional relevant covariates. In particular, the wage inequality would result from a potential increase in the WFH feasibility of some professions existing in the labour market is fully compatible with the SBTC theory (Acemoglu 2002).

Fifth, we replicated all estimates in our main analysis without applying individual weights. Indeed, although the application of individual weights ensures the representativeness of our sample to the total population, non-response biases these weights have the objective to solve may be somehow related to the probability to perform a profession with a lower (or higher) level of WFH feasibility. Appendices 2.9 and 2.14 show that results of this further sensitivity analysis overall confirm our main conclusions.

\subsection{Controlling for selection bias: the IPW methodology}

Finally, in order to control for selection bias in the WFH feasibility for the two groups of employees, we also estimate the influence of the WFH feasibility on the logarithm of the labour income distribution by adopting a non-parametric framework allowing for flexibly control for potential confounders. Specifically, we implement an inverse probability weighting (IPW) estimator as proposed by Di Nardo et al. (1996) and Firpo (2007). This method estimates quantiles for two counterfactual distributions, one if every employee had a high WFH feasibility, the other if they had all a low WFH 
feasibility, where in the first stage the conditional probability of performing an profession with a low(high) WFH feasibility is estimated by using a Probit model, given a set of characteristics. In other words, the counterfactual density can be determined by a 'reweighting' function that estimates the probability of having a WFH feasibility as a function of all the other characteristics to be kept constant (Leonida et al. 2020; Scicchitano et al. 2020).

The definition of the set of observable conditioning variables is crucial to ensure the unconfoundedness assumption (Albanese and Gallo 2020), i.e. the potential increase in the labour income of employees in different levels of WFH feasibility is independent of the actual feasibility level. In this robustness check, we adopt the same set of covariates defined in Sect. 4 to estimate UPEs as we believe it considerably reduces the role of unobserved heterogeneity between the two groups of employees. Nonetheless, even though controlling for a large number of relevant characteristics that may affect both outcome and treatment selection, we cannot avoid that other unobservable confounding factors may be still in place.

Table 6 reports estimated coefficients on the mean and nine decile values from the IPW approach. The effect of having a high WFH feasibility on the average income is equal to $+3.5 \%$, while it is equal to $+5.0 \%$ at the median and to $+16.3 \%$ at the last decile of labour income.

Looking at estimates by group of employees, results illustrated in Table 6 seem to be overall in line with conclusions stated in Sect. 5.1. In fact, high levels of WFH feasibility would go in mainly favour of male, aged 51-64, and graduated employees, as well as those living in the areas have been more affected by the recent COVID-19 pandemic (i.e. northern provinces of the country). In conclusion, results based on the IPW estimation approach indicate that the estimated influence of the WFH feasibility on income distribution is not substantially distorted by a selection bias, thus strengthening the evidence obtained through the RIF method.

\section{Conclusions}

WFH is considered an important solution in developed societies for the coexistence with the COVID-19 virus, because it allows to work while keeping the social distancing. Besides, since the absence of herd immunity against COVID-19 suggests that a second wave of the virus transmission is possible (Leung et al. 2020), the WFH may become a long-lasting solution. The current crisis has forced many companies to a massive use of WFH and, for some of them, to think about a 'new normal' (https://www.upwork.com/resources/how-to-adjust-to-the-new-normal-of-remotework) way of working as a future challenge. As a result, the study of the potential socio-economic outcomes related to the WFH spread is becoming a more and more relevant topic for researchers worldwide.

Based on unconditional quantile regression methods, this paper represents the first contribute showing how a future increase in the WFH feasibility would be related to changes in labour income levels and inequality. To do that, we focus on Italy as an interesting case study, because both it has been one of the countries most affected by the novel coronavirus and it was the European country with the lowest share of teleworkers before the crisis (Eurofound and ILO 2017). Our analysis relies on a 


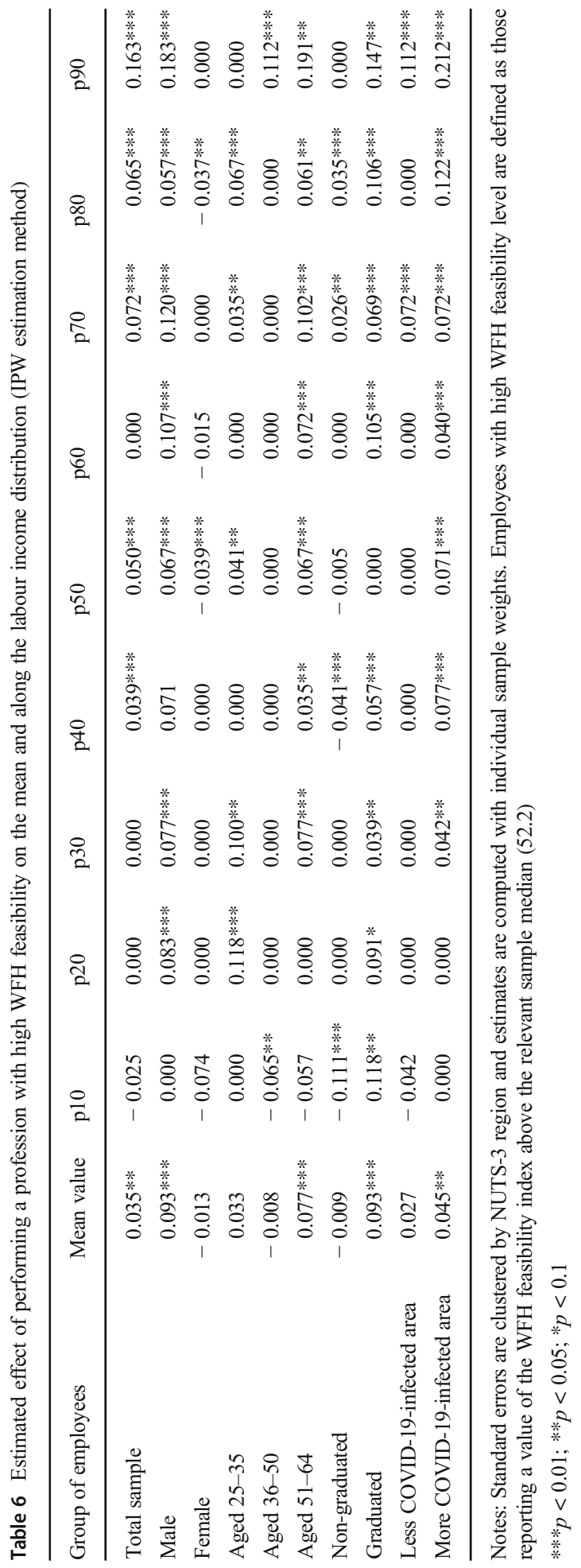


unique dataset merging the INAPP-PLUS survey and Italian equivalent of the US $\mathrm{O} * \mathrm{NET}$ repertoire, thus the ICP.

Assuming a long-lasting increase in the WFH feasibility levels (i.e. swapping $10 \%$ of employees with a low level of WFH feasibility with other employees with a high one), our results show that this marginal change would have potential 'collateral effects' on income inequality among employees that should not be underestimated. An increase of the WFH feasibility levels of professions would be associated to a growth of the average labour income, probably because of their higher productivity. However, it would also be associated with a rise of labour income inequality among employees, because it would tend to benefit more male, older, graduated, and high-paid employees. It also has to be reported that a positive shift in the WFH feasibility levels would be more in favour of employees living in provinces have been affected the most by COVID-19 infections, thus those areas will probably suffer more demographic and economic effects of the pandemic. Our results hold after a number of robustness checks, regarding different definitions of interest variables, income inequality indexes, model specifications, and controls for skill heterogeneity and selection bias.

Given that the shares of professions can be performed from home may clearly differ by country (Dingel and Neiman 2020; Boeri et al. 2020), the intrinsic functioning of the RIF regressions methodology provides the relevant advantage to be easily extended according to the specific assumptions adopted on the employees shares swap (related to, e.g. economics structure, innovation spread, type of technological change, political decisions). In other words, the flexible methodology here adopted allows to researchers and (of course) policymakers to somehow 'forecast' potential consequences on income levels related to their decisions on the increase of WFH opportunities.

In conclusion, WFH risks to exacerbate pre-existing inequalities in the labour market, especially if it will not be adequately regulated. In this respect, during a health emergency, ex post policies aimed at alleviating inequality in the short run, like income support measures broad enough to cover most vulnerable employees, should be implemented.

Unemployment insurance (UI), for example, is playing a critical role in many western countries during the pandemic. In the USA, by late June, 36 million individuals either were receiving or had applied for unemployment benefits (Shierholz 2020) and the general idea is that expanded UI should remain in the USA, with adjustments made according to unemployment rate changes (Furman 2020). Also, in Italy and other European countries, multiple employment and social initiatives where implemented as reported by the OECD (2020). The problematic aspect is that, while UI has a large, positive effect on the demand side by supporting consumption and thus all the economy, it may also negatively affect labour supply, suggesting that the amount and the duration should be well tailored among countries. The effect of unemployment benefit on unemployment spell duration have been largely investigated (Card and Levine 2000; Lalive et al. 2006; van Ours and Vodopivec 2006) and results usually show that the higher the benefit the higher the unemployment duration is. This can lead to an opportunistic behaviour while searching for a job. As for Italy, according to recent results, the unemployment benefit eligibility was proved to affect worker layoffs, particularly for jobs started after the onset of the Great Recession and in the South (Albanese et al. 2020).

This crisis gives a boost to WFH forcing companies to invest and reorganise work even remotely. This push has to be transformed into something structural in a new way 
of producing and managing flexible work practices within companies, but not all firms are able to do that (Dosi et al. 2019; Cetrulo et al. 2019). We need a massive reorganisation of work (Cetrulo et al. 2020), particularly in the field of reengineering of production processes based on new digital technologies and on the possibility offered in terms of work from home. This requires new skills not only for workers but also for managers and entrepreneurs. As Brynjolfsson et al. (2020) explain, once companies and workers will incur significant fixed costs for remote work due to technologies, changes in production processes and updating of human capital, it is likely that they will no longer want to go back (or at least not exactly to the same starting point) and therefore the WFH is intended to be extended over time. If it will be the case, temporary income support measures will not be sufficient anymore to compensate potentially increasing wage differentials.

Long-term interventions filling potential knowledge gaps are going to be therefore necessary to prevent the rise of inequalities in the labour market. First, childcare facilities and financial support to households with children, are required to facilitate the adoption of WFH especially for female employees with young children (Pouliakas 2020). In the same direction, Checchi (2006) suggests that a higher average educational attainment is correlated with lower differences in educational achievement among the population, leading to reduced income inequality. Second, not surprising, two set of education policies may be suggested: increasing the school enrolment rate and improving the training courses. The latter would play an important role in reducing unequal distribution of benefits related to an increase of WFH opportunities, by increasing human capital and favouring its complementarities with technology (Acemoglu 1997).

The most important issue that several developed countries has to solve in this period concerns how to restart the national economy avoiding, at the same time, a rise of the contagion risk in the so-called Phase 2, thus the one on which people live with the virus under control (Favero et al. 2020). While many countries are designing exit strategies by also increasing the share of people working remotely, the evidence we provide in this paper can inform policymakers on the potential effects of such a decision and 'forced innovation' in terms of wage inequality. Our analysis may therefore represent a useful starting point to select policies that would assist, especially in developed countries, a possible structural re-organisation of the WFH and the labour market in general.

Acknowledgements The authors would like to thank the anonymous referees for helpful comments and suggestions. We thank Gaetano Basso, Irene Brunetti, Mauro Caselli, the Editor-in-Chief, Klaus F. Zimmermann, as well as the four referees for many useful comments that have significantly improved the paper. The views expressed in this paper are those of the authors and do not necessarily reflect those of INAPP.

Availability of data and material Individuals interested in data used in this analysis can apply for them from the National Institute for Public Policies Analysis (INAPP), by visiting the following site: https://inapp. org/it/dati.

\section{Compliance with ethical standards}

Conflicts of interest The authors declare that they have no conflict of interest.

Code availability Available upon request. 


\section{Appendix 1. Descriptive statistics and additional estimates}

Table 7 Variable description

\begin{tabular}{ll}
\hline Variable & Description \\
\hline Annual gross labour income & $\begin{array}{c}\text { Continuous variable representing the annual gross labour income. All } \\
\text { re-centred influence functions on distributional statistics are based } \\
\text { on this variable. }\end{array}$
\end{tabular}

High working from home (WFH) feasibility

Female

Aged 36-50

Aged 51-64

Upper secondary education

Tertiary education

Migrant within macro-region

Migrant within country

Foreign migrant

Married

Household size $=2$

Household size $=3$

Household size $=4$

Household size $=5$ or more

Presence of minors

Small municipality

Medium municipality

Big municipality

Metropolitan city

Centre

South

Part-time open-ended worker

Temporary worker and other
Binary variable reporting the level of WFH feasibility. The WFH feasibility is measured, for each occupation at 5-digit ISCO classification level, through a composite index recently introduced by Barbieri et al. (2020). This index relies on replies to seven questions in the ICP 2013 survey questionnaire regarding the following: (i) the importance of performing general physical activities (which enters reversely); (ii) the importance of working with computers; (iii) the importance of manoeuvring vehicles, mechanical vehicles or equipment (reversely); (iv) the requirement of face-to-face interactions (reversely); (v) the dealing with external customers or with the public (reversely); (vi) the physical proximity (reversely); and (vii) the time spent standing (reversely). The WFH feasibility is calculated as average of the listed 7 items and ranges from 0 to 100 .

Binary variable is equal to 1 for those having an index value over the sample mean (i.e. 52.2), and 0 otherwise.

Binary variable taking value 1 for female, 0 for male

Binary variables representing the age group of individuals. The reference category is aged $25-35$.

Binary variables representing the highest education level achieved. The reference category is composed by lower secondary education (or lower education level).

Binary variables representing the migration status. An individual is 'migrant within macro-region' if her region of birth and her region of residence belong to the same macro-region (i.e. North, Centre, or South). An individual is 'migrant within country' if her region of birth belongs to a different macro-region with respect to her region of residence. An individual is 'foreign migrant' if she moves from outside Italy. The reference category is local.

Binary variable taking value 1 for married people, and 0 otherwise.

Binary variables representing the household size. The reference category is single person (or household size $=1$ ).

Binary variable taking value 1 for people living in households with at least 1 minor child, and 0 otherwise.

Binary variables representing the size of the municipality of residence. Small municipality has a number of inhabitants between 5000 and 20,000, Medium municipality has 20,000-50,000 inhabitants, Big municipality counts 50,000-250,000 inhabitants, and Metropolitan city has 250,000 or more inhabitants. The reference category is very small municipality (number of inhabitants lower than 5000).

Binary variables representing the macro-region of residence. The reference category is North.

Binary variables representing the type of job contract. The reference category is full-time open-ended worker. 
Table 7 (continued)

\begin{tabular}{ll}
\hline Variable & Description \\
\hline Public servant & $\begin{array}{c}\text { Binary variable taking value } 1 \text { for employees working in the public } \\
\text { sector, and } 0 \text { otherwise. } \\
\text { Less COVID-19-infected area } \\
\text { Variable representing the degree of COVID-19 infection at provincial } \\
\text { level. The infection degree is measured as the incidence of } \\
\text { COVID-19 cases on total population at provincial level. People live } \\
\text { in a 'more COVID-19-infected' area if their province of residence } \\
\text { reports an infection incidence over the sample median (i.e. 3.2\%o). } \\
\text { Alternatively, they live in a 'less COVID-19-infected' area. Data on } \\
\text { the overall COVID-19 cases at provincial level are provided by the } \\
\text { Italian Civil Protection Department (2020) and refers to the period } \\
\text { between 24 February and } 5 \text { May 2020. }\end{array}$ \\
\hline
\end{tabular}

Table 8 Sample composition, mean and Gini index of annual labour income, mean value of the WFH feasibility index and share of employees with high feasibility level by economic sector of activity

\begin{tabular}{|c|c|c|c|c|c|c|}
\hline \multirow[t]{2}{*}{ Economic sector of activity } & \multicolumn{2}{|c|}{ Sample composition } & \multicolumn{2}{|c|}{ Annual labour income } & \multicolumn{2}{|c|}{ WFH feasibility } \\
\hline & Mean & Std. Dev. & Mean & Gini index & Mean & $\begin{array}{l}\% \text { of employees } \\
\text { with high feasibility }\end{array}$ \\
\hline A. Agriculture & 0.024 & 0.153 & 20,960 & 0.270 & 49.8 & 35.9 \\
\hline B. Extraction & 0.006 & 0.077 & 35,770 & 0.380 & 54.3 & 43.7 \\
\hline C. Manufacturing & 0.168 & 0.374 & 27,650 & 0.252 & 52.4 & 42.9 \\
\hline D. Energy, gas & 0.016 & 0.127 & 35,084 & 0.356 & 56.5 & 60.6 \\
\hline E. Water, waste & 0.005 & 0.068 & 38,049 & 0.424 & 51.0 & 32.7 \\
\hline F. Construction & 0.029 & 0.167 & 25,176 & 0.242 & 49.6 & 39.8 \\
\hline G. Trade & 0.098 & 0.298 & 23,662 & 0.305 & 48.4 & 38.6 \\
\hline H. Transportation & 0.049 & 0.216 & 27,445 & 0.262 & 49.6 & 25.8 \\
\hline I. Hotel, restaurants & 0.035 & 0.184 & 22,965 & 0.366 & 39.0 & 16.2 \\
\hline J. Information, comm. & 0.040 & 0.196 & 27,866 & 0.275 & 63.8 & 81.9 \\
\hline K. Finance, insurance & 0.038 & 0.191 & 30,730 & 0.277 & 64.6 & 84.2 \\
\hline L. Real estate & 0.003 & 0.053 & 23,995 & 0.236 & 58.2 & 71.0 \\
\hline M. Professional services & 0.062 & 0.241 & 27,863 & 0.341 & 59.9 & 72.3 \\
\hline N. Other business services & 0.040 & 0.196 & 25,076 & 0.222 & 62.6 & 79.9 \\
\hline O. Public administration & 0.070 & 0.254 & 27,581 & 0.254 & 59.8 & 72.3 \\
\hline P. Education & 0.124 & 0.329 & 25,040 & 0.194 & 47.9 & 35.2 \\
\hline Q. Health & 0.105 & 0.307 & 25,060 & 0.281 & 44.6 & 32.8 \\
\hline R. Sport, recreational activities & 0.012 & 0.109 & 23,277 & 0.302 & 52.6 & 55.5 \\
\hline S. Other services & 0.068 & 0.252 & 21,895 & 0.316 & 53.3 & 52.7 \\
\hline T. Household activities & 0.008 & 0.087 & 16,822 & 0.232 & 53.6 & 57.3 \\
\hline U. International organisations & 0.002 & 0.046 & 31,033 & 0.339 & 58.9 & 57.0 \\
\hline Total sample & - & - & 25,979 & 0.280 & 52.4 & 48.2 \\
\hline
\end{tabular}

Notes: All descriptive statistics are computed with individual sample weights. Employees with high WFH feasibility level are defined as those reporting a value of the WFH feasibility index above the relevant sample median 
Table 9 Unconditional effects on the mean and Gini index in the total sample

\begin{tabular}{|c|c|c|c|c|}
\hline \multirow[t]{2}{*}{ Variable } & \multicolumn{2}{|l|}{ Mean value } & \multicolumn{2}{|l|}{ Gini index } \\
\hline & UE & UPE & UE & UPE \\
\hline High WFH feasibility & $258.86^{* * *}$ & 97.98 & $0.004 * *$ & $0.004 * *$ \\
\hline Female & & $-609.03 * * *$ & & $-0.005^{* * *}$ \\
\hline Aged 36-50 & & $350.56 * * *$ & & $0.004 * *$ \\
\hline Aged 51-64 & & $508.34 * * *$ & & $0.005^{*}$ \\
\hline Upper secondary education & & $369.68 * * *$ & & -0.001 \\
\hline Tertiary education & & $967.14 * * *$ & & $0.005 * *$ \\
\hline Migrant within macro-region & & 215.77 & & 0.008 \\
\hline Migrant within country & & -10.81 & & 0.001 \\
\hline Foreign migrant & & -61.27 & & 0.005 \\
\hline Married & & $290.77 * * *$ & & $0.005^{*}$ \\
\hline Household size $=2$ & & -102.24 & & -0.001 \\
\hline Household size $=3$ & & $-198.23 *$ & & -0.003 \\
\hline Household size $=4$ & & -75.66 & & -0.000 \\
\hline Household size $=5$ or more & & 48.40 & & 0.004 \\
\hline Presence of minors & & -63.58 & & -0.004 \\
\hline Small municipality & & 84.14 & & 0.001 \\
\hline Medium municipality & & -46.48 & & -0.001 \\
\hline Big municipality & & 27.54 & & 0.002 \\
\hline Metropolitan city & & -22.35 & & -0.000 \\
\hline Centre & & $-186.27 * * *$ & & -0.000 \\
\hline South & & $-154.14 *$ & & $0.005 * *$ \\
\hline Part-time open-ended worker & & $-838.13 * * *$ & & $0.014 * * *$ \\
\hline Temporary worker and other & & $-650.36^{* * * *}$ & & $0.010 * * *$ \\
\hline Public servant & & 12.68 & & $-0.005^{* *}$ \\
\hline Constant & $2473.14 * * *$ & $2080.79 * * *$ & $0.026 * * *$ & $0.017 * * *$ \\
\hline Activity sector dummies & No & Yes & No & Yes \\
\hline Observations & 14,307 & 14,307 & 14,307 & 14,307 \\
\hline$R$-squared & 0.002 & 0.061 & 0.001 & 0.016 \\
\hline
\end{tabular}

Notes: Standard errors are clustered by NUTS-3 region and estimates are computed with individual sample weights. Employees with high WFH feasibility level are defined as those reporting a value of the WFH feasibility index above the relevant sample median

$* p<0.1$; ** $p<0.05$; *** $p<0.01$ 


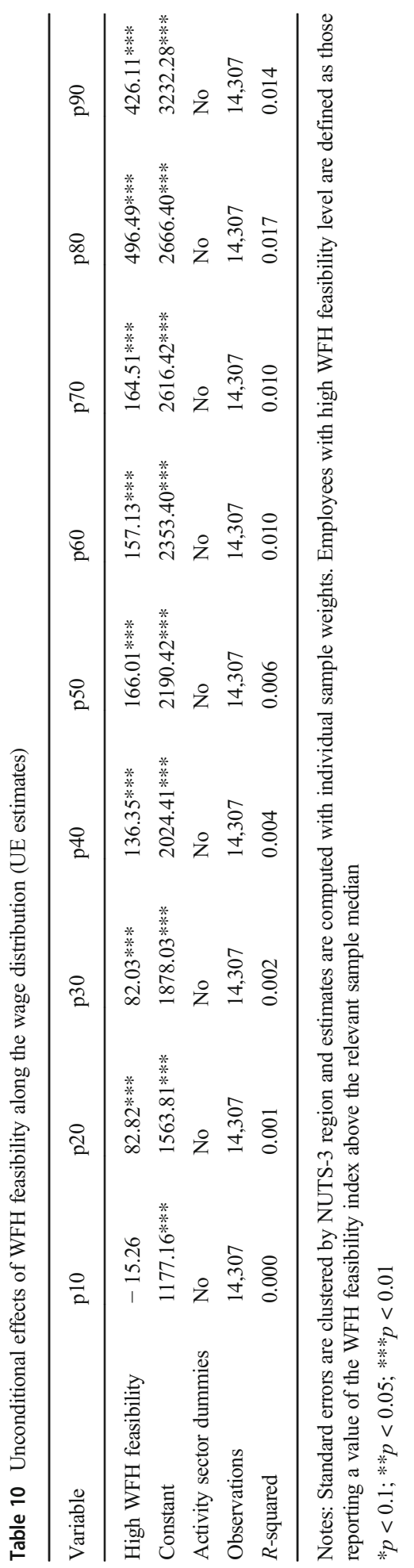




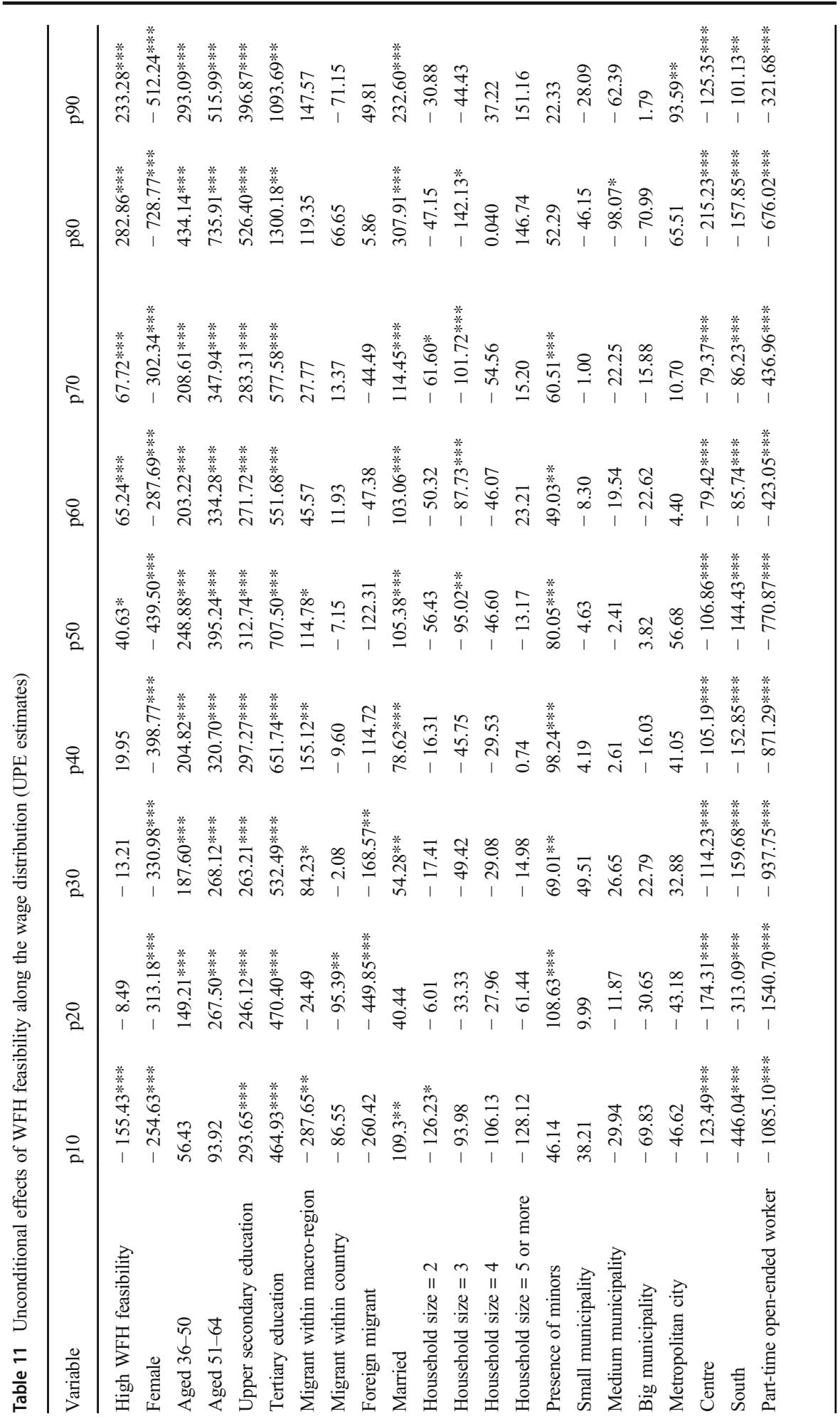




$$
\text { 罆 }
$$


Table 12 Unconditional effects on mean value and Gini index by item of the WFH feasibility index (excluding employees with index value equals to 0 )

\begin{tabular}{|c|c|c|c|c|c|}
\hline \multirow{2}{*}{$\begin{array}{l}\text { Item of the } \\
\text { multidimensional index }\end{array}$} & \multirow{2}{*}{$\begin{array}{l}\text { Threshold } \\
\text { value }\end{array}$} & \multicolumn{2}{|l|}{ Mean value } & \multicolumn{2}{|l|}{ Gini index } \\
\hline & & UE & UPE & UE & UPE \\
\hline Performing physical activities ${ }^{\mathrm{a}}$ & 82.5 & $383.22 * * *$ & $217.80 * * *$ & -0.000 & 0.002 \\
\hline Working with computers & 50.0 & $459.96^{* * *}$ & $202.18 * * *$ & 0.000 & 0.000 \\
\hline Manoeuvring vehicles or machines ${ }^{\mathrm{a}}$ & 95.6 & -101.23 & -78.13 & -0.002 & -0.003 \\
\hline Face-to-face discussion ${ }^{\mathrm{a}}$ & 22.0 & $-274.30^{* * * *}$ & -171.03 & 0.002 & 0.001 \\
\hline Dealing with customers and public ${ }^{\mathrm{a}}$ & 46.0 & $-243.08 * * *$ & $-205.62 * * *$ & -0.002 & -0.003 \\
\hline Physical proximitya & 63.8 & $-394.14 * * *$ & $-208.15 * * *$ & $-0.005 * * *$ & $-0.005^{* * *}$ \\
\hline Spending time standing ${ }^{\mathrm{a}}$ & 47.0 & $469.31 * * *$ & $292.61 * * *$ & 0.002 & $0.003 * *$ \\
\hline WFH feasibility (total) & 52.2 & $258.86^{* * *}$ & 97.98 & $0.004 * *$ & $0.004 * *$ \\
\hline
\end{tabular}

Notes: Standard errors are clustered by NUTS-3 region and estimates are computed with individual sample weights. Unconditional effects refer to the variable of interest (i.e. high index value) only. Employees with high index value are defined, for each item, as those reporting a value of the single index over the threshold value illustrated in the table (i.e. the sample median). UE estimates are based on a model specification which only includes the variable of interest, while for UPE estimates additional covariates are included in the model (see Sect. 4)

$* p<0.1 ; * * p<0.05 ; * * * p<0.01$

a The index referring to the specific item is reversely considered

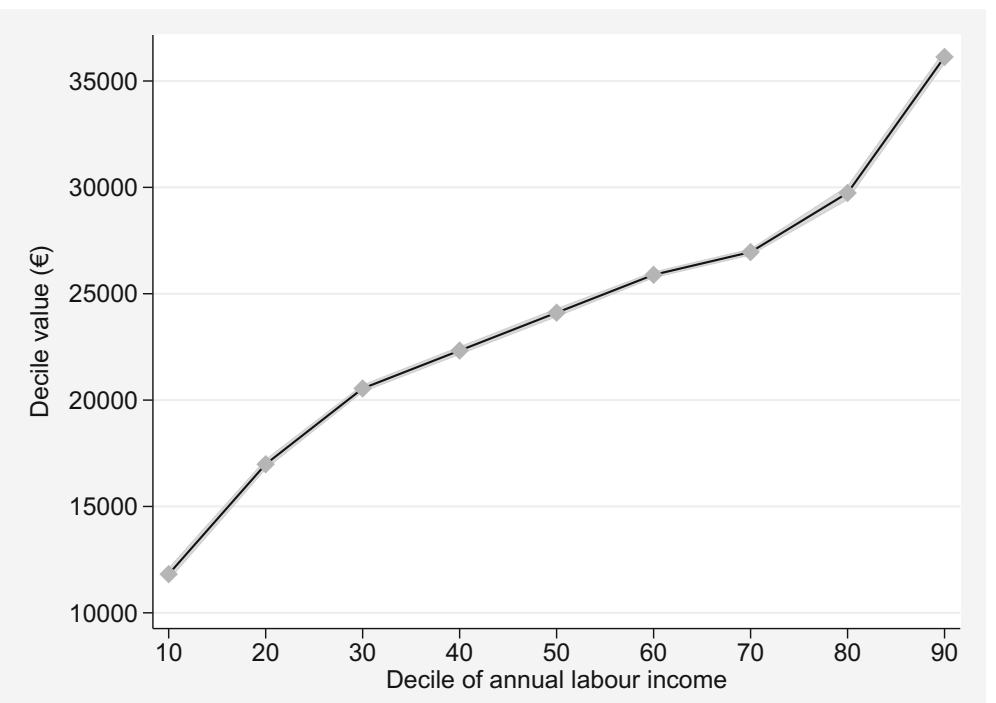

Fig. 7 Income values by decile of annual labour income. Notes: All descriptive statistics are computed with individual sample weights. Shadowed area report confidence intervals at $95 \%$ level. 

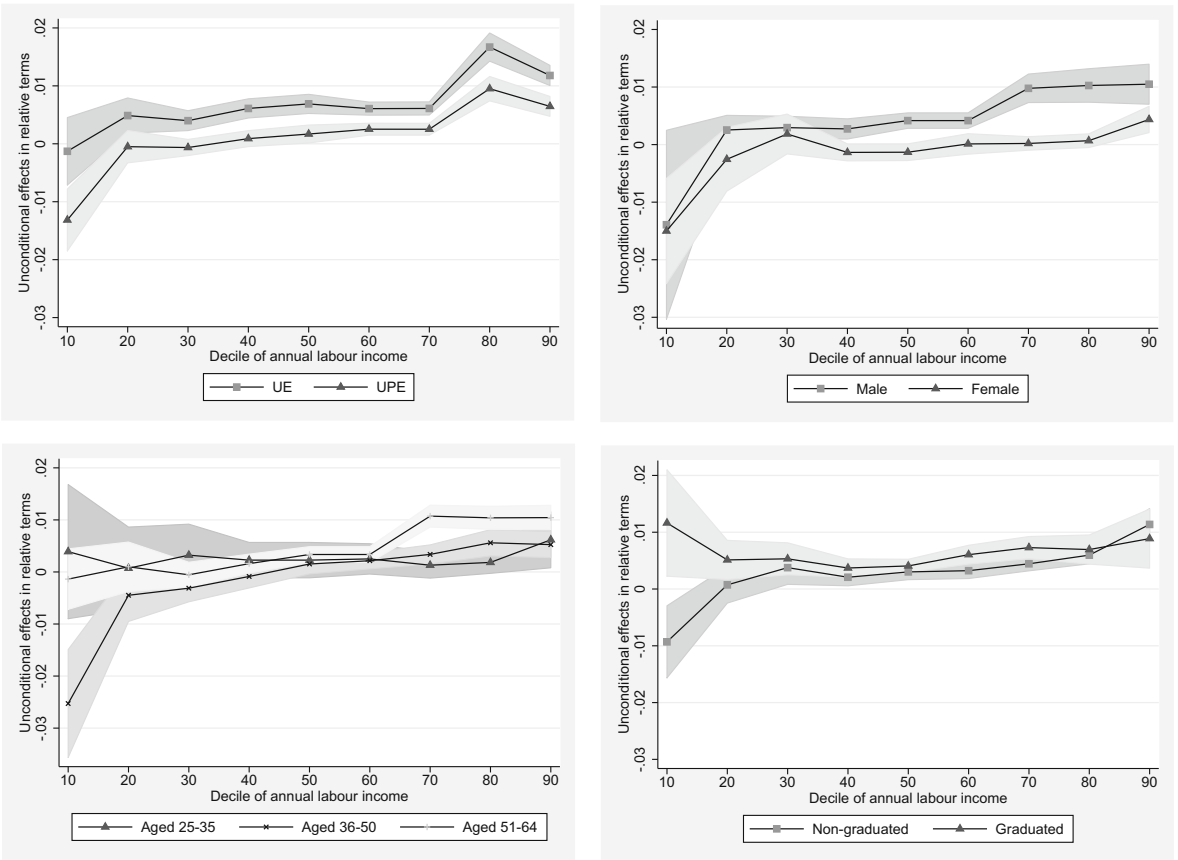

Fig. 8 Unconditional effects of a positive shift in the WFH feasibility along labour income distribution (relatively to the point estimates of deciles). Notes: Standard errors are clustered by NUTS-3 region and estimates are computed with individual sample weights. Shadowed area reports confidence intervals at $90 \%$ level. The figures present coefficients reported in Fig. 4 divided by the point estimation value for the specific decile in the specific subgroup of employees. Employees with high WFH feasibility level are defined as those reporting a value of the WFH feasibility index above the relevant sample median. UE estimates are based on a model specification which only includes the variable of interest, while for UPE estimates, additional covariates are included in the model (see Sect. 4). Estimates by employees' characteristics refer to the UPE specification 


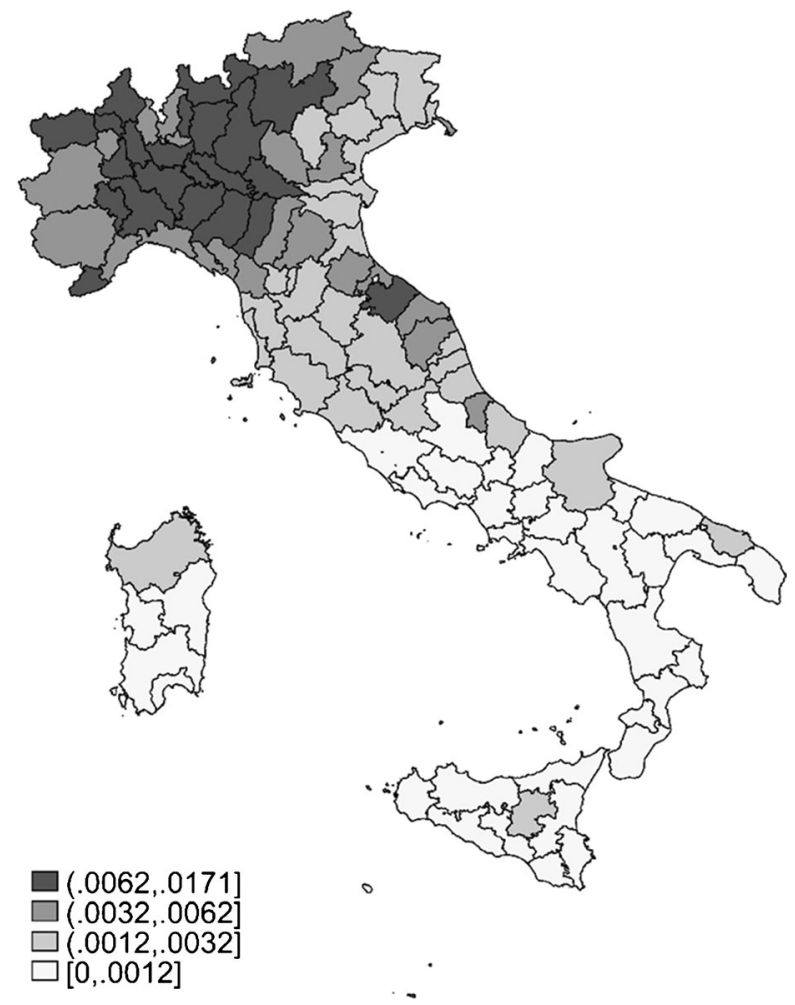

Fig. 9 COVID-19 infection incidence by province. Notes: All descriptive statistics are computed with individual sample weights. The choropleth map is based on a quantile method, so that class breaks coincide with quartiles of COVID-19 infection incidence at provincial level in the analysis sample. Source: Elaboration of the authors on data by the Italian Civil Protection Department (2020). Accessed 5 May 2020 


\section{Appendix 2. Robustness checks}

Table 13 Unconditional effects on the mean and Gini index of labour income considering only full-time open-ended employees

\begin{tabular}{|c|c|c|c|c|}
\hline \multirow[t]{2}{*}{ Group of employees } & \multicolumn{2}{|c|}{ Mean value } & \multicolumn{2}{|c|}{ Gini index } \\
\hline & UE & UPE & UE & UPE \\
\hline Total sample & $390.45 * * *$ & $209.16^{* *}$ & $0.004 *$ & 0.003 \\
\hline Male & $544.90 * * *$ & $329.72 * *$ & 0.005 & 0.004 \\
\hline Female & $193.42 * * *$ & 36.94 & $0.003 *$ & 0.001 \\
\hline Aged 25-35 & $488.21^{* * *}$ & $541.49^{* *}$ & 0.007 & 0.012 \\
\hline Aged 36-50 & 205.19 & 30.96 & 0.001 & 0.000 \\
\hline Aged 51-64 & $595.26^{* * *}$ & $315.36^{* * *}$ & $0.007 * * *$ & 0.005 \\
\hline Non-graduated & $281.71 * *$ & $287.87 * * *$ & 0.003 & 0.004 \\
\hline Graduated & $473.55^{* * *}$ & $254.05^{* *}$ & $0.006 * * *$ & 0.001 \\
\hline Less COVID-19-infected area & $361.24 * * *$ & 219.28 & 0.004 & 0.004 \\
\hline More COVID-19-infected area & $421.96^{* * *}$ & $201.77 * *$ & 0.004 & 0.003 \\
\hline
\end{tabular}

Notes: Standard errors are clustered by NUTS-3 region and estimates are computed with individual sample weights. The table presents coefficients of the variable of interest (i.e. high WFH feasibility) only. Employees with high WFH feasibility level are defined as those reporting a value of the WFH feasibility index above the relevant sample median. UE estimates are based on a model specification which only includes the variable of interest, while for UPE estimates, additional covariates are included in the model (see Sect. 4)

$* p<0.1 ; * * p<0.05 ; * * * p<0.01$

Table 14 Unconditional effects on the mean and Gini index of labour income (self-employees included in the sample)

\begin{tabular}{|c|c|c|c|c|}
\hline \multirow[t]{2}{*}{ Group of employees } & \multicolumn{2}{|c|}{ Mean value } & \multicolumn{2}{|c|}{ Gini index } \\
\hline & UE & UPE & UE & UPE \\
\hline Total sample & $206.56^{* * *}$ & 58.59 & $0.002 *$ & $0.002 *$ \\
\hline Male & $360.05 * * *$ & $178.31 *$ & 0.002 & 0.002 \\
\hline Female & $109.58 * * *$ & -61.77 & $0.003 *$ & 0.001 \\
\hline Aged 25-35 & $226.40 * * *$ & 129.92 & 0.003 & 0.005 \\
\hline Aged $36-50$ & 37.39 & -68.21 & 0.001 & 0.001 \\
\hline Aged 51-64 & $435.29 * * *$ & $183.19 *$ & $0.004 * *$ & 0.004 \\
\hline Non-graduated & 95.32 & 104.15 & 0.001 & 0.002 \\
\hline Graduated & $310.01 * * *$ & $166.63 * *$ & $0.005 * * *$ & 0.001 \\
\hline Less COVID-19-infected area & $159.80 *$ & 33.68 & 0.001 & 0.002 \\
\hline More COVID-19-infected area & $262.78 * * *$ & 77.97 & $0.003 *$ & $0.003 * *$ \\
\hline
\end{tabular}

Notes: Standard errors are clustered by NUTS-3 region and estimates are computed with individual sample weights. The table presents coefficients of the variable of interest (i.e. high WFH feasibility) only. Employees with high WFH feasibility level are defined as those reporting a value of the WFH feasibility index above the relevant sample median. UE estimates are based on a model specification which only includes the variable of interest, while for UPE estimates, additional covariates are included in the model (see Sect. 4)

$* p<0.1 ; * * p<0.05 ; * * * p<0.01$ 
Table 15 Unconditional effects on the mean and Gini index of labour income (variable of interest with continuous specification)

\begin{tabular}{|c|c|c|c|c|}
\hline \multirow[t]{2}{*}{ Group of employees } & \multicolumn{2}{|l|}{ Mean value } & \multicolumn{2}{|l|}{ Gini index } \\
\hline & UE & UPE & UE & UPE \\
\hline Total sample & $90.22 * * *$ & 16.03 & 0.000 & 0.000 \\
\hline Male & $151.03 * * *$ & 61.74 & 0.001 & 0.001 \\
\hline Female & $40.55^{* *}$ & -16.57 & -0.000 & -0.001 \\
\hline Aged 25-35 & $111.76^{* * * *}$ & $69.50 * *$ & 0.001 & 0.002 \\
\hline Aged 36-50 & 30.51 & -32.03 & -0.000 & -0.000 \\
\hline Aged 51-64 & $151.52 * * *$ & 41.02 & $0.001 * *$ & 0.001 \\
\hline Non-graduated & $61.58 * *$ & 35.96 & 0.000 & 0.000 \\
\hline Graduated & $121.99 * * *$ & 50.39 & $0.002 * * *$ & 0.000 \\
\hline Less COVID-19-infected area & 55.41 & -11.74 & -0.000 & -0.000 \\
\hline More COVID-19-infected area & $128.89 * * *$ & $45.24 * * *$ & 0.001 & 0.001 \\
\hline
\end{tabular}

Notes: Standard errors are clustered by NUTS-3 region and estimates are computed with individual sample weights. The table presents coefficients of the variable of interest (i.e. WFH feasibility index) only. The WFH feasibility index is a multidimensional index ranging from 0 to 100 . UE estimates are based on a model specification which only includes the variable of interest, while for UPE estimates, additional covariates are included in the model (see Sect. 4)

$* p<0.1 ; * *<0.05 ; * * * p<0.01$

Table 16 Unconditional effects on mean value and Gini index by item of the WFH feasibility index (variable of interest with continuous specification)

\begin{tabular}{|c|c|c|c|c|}
\hline \multirow[t]{2}{*}{ Item of the multidimensional index } & \multicolumn{2}{|l|}{ Mean value } & \multicolumn{2}{|l|}{ Gini index } \\
\hline & UE & UPE & UE & UPE \\
\hline Performing physical activities ${ }^{\mathrm{a}}$ & $120.66^{* * * *}$ & $55.35^{* * * *}$ & -0.0003 & -0.0001 \\
\hline Working with computers & $108.46 * * *$ & $41.14 * * *$ & -0.0003 & -0.0003 \\
\hline Manoeuvring vehicles or machines ${ }^{\mathrm{a}}$ & -13.52 & 7.55 & 0.0004 & $0.0009^{*}$ \\
\hline Face-to-face discussion ${ }^{\mathrm{a}}$ & $-189.91 * * *$ & $-149.25 * * *$ & 0.0007 & -0.0002 \\
\hline Dealing with customers and public ${ }^{\mathrm{a}}$ & $-61.80 * * *$ & $-61.91 * * *$ & $-0.0008^{*}$ & -0.0008 \\
\hline Physical proximity ${ }^{a}$ & $-165.26^{* * *}$ & $-85.74 * * *$ & $-0.0012 * * *$ & $-0.0013^{* * *}$ \\
\hline Spending time standing ${ }^{\mathrm{a}}$ & $102.98 * * *$ & $60.60 * * *$ & 0.0003 & 0.0006 \\
\hline WFH feasibility (total) & $90.22 * * *$ & 16.03 & 0.0004 & 0.0004 \\
\hline
\end{tabular}

Notes: Standard errors are clustered by NUTS-3 region and estimates are computed with individual sample weights. Unconditional effects refer to the variable of interest (i.e. single index value) only. Each index considered ranges from 0 to 100 . UE estimates are based on a model specification which only includes the variable of interest, while for UPE estimates, additional covariates are included in the model (see Sect. 4)

$* p<0.1 ; * *<<0.05 ; * * * p<0.01$

a The index referring to the specific item is reversely considered 
Table 17 Unconditional effects on the mean log deviation and Atkinson index $(\mathrm{e}=1)$

\begin{tabular}{|c|c|c|c|c|}
\hline \multirow[t]{2}{*}{ Group of employees } & \multicolumn{2}{|c|}{ Mean log deviation } & \multicolumn{2}{|c|}{ Atkinson index $(\mathrm{e}=1)$} \\
\hline & UE & UPE & UE & UPE \\
\hline Total sample & 0.003 & $0.004 *$ & 0.003 & $0.003 *$ \\
\hline Male & 0.002 & 0.004 & 0.002 & 0.003 \\
\hline Female & $0.003 * *$ & 0.002 & $0.003 * *$ & 0.002 \\
\hline Aged 25-35 & 0.005 & $0.008^{*}$ & 0.004 & $0.007 *$ \\
\hline Aged 36-50 & 0.000 & 0.002 & 0.000 & 0.002 \\
\hline Aged 51-64 & $0.006^{* *}$ & 0.004 & $0.005 * *$ & 0.004 \\
\hline Non-graduated & 0.002 & 0.003 & 0.002 & 0.003 \\
\hline Graduated & $0.005^{* *}$ & 0.000 & $0.004 * *$ & 0.000 \\
\hline Less COVID-19-infected area & 0.002 & 0.004 & 0.002 & 0.003 \\
\hline More COVID-19-infected area & 0.004 & 0.003 & 0.003 & 0.003 \\
\hline
\end{tabular}

Notes: Standard errors are clustered by NUTS-3 region and estimates are computed with individual sample weights. Unconditional effects refer to the variable of interest (i.e. High WFH feasibility) only. Employees with high WFH feasibility level are defined as those reporting a value of the WFH feasibility index above the relevant sample median. UE estimates are based on a model specification which only includes the variable of interest, while for UPE estimates, additional covariates are included in the model (see Sect. 4)

$* p<0.1 ; * * p<0.05 ; * * * p<0.01$ 


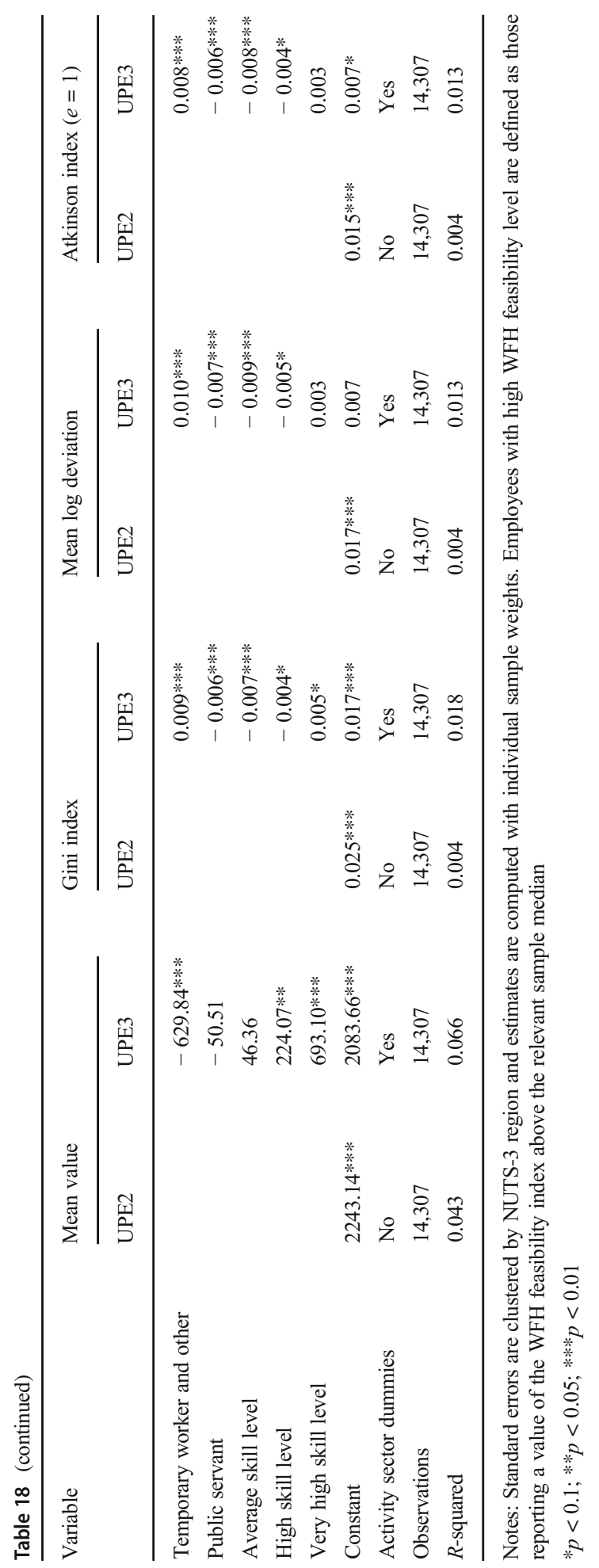




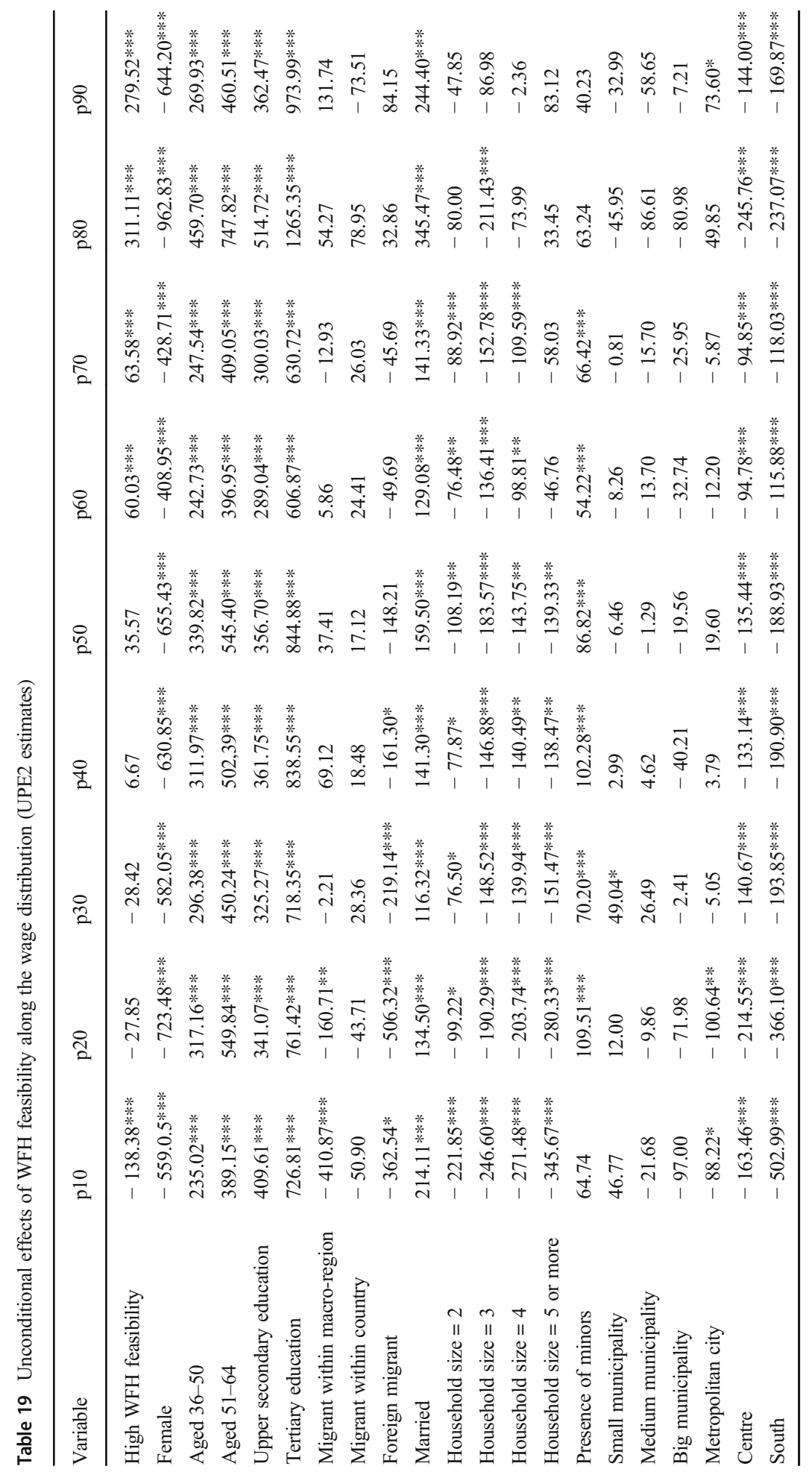




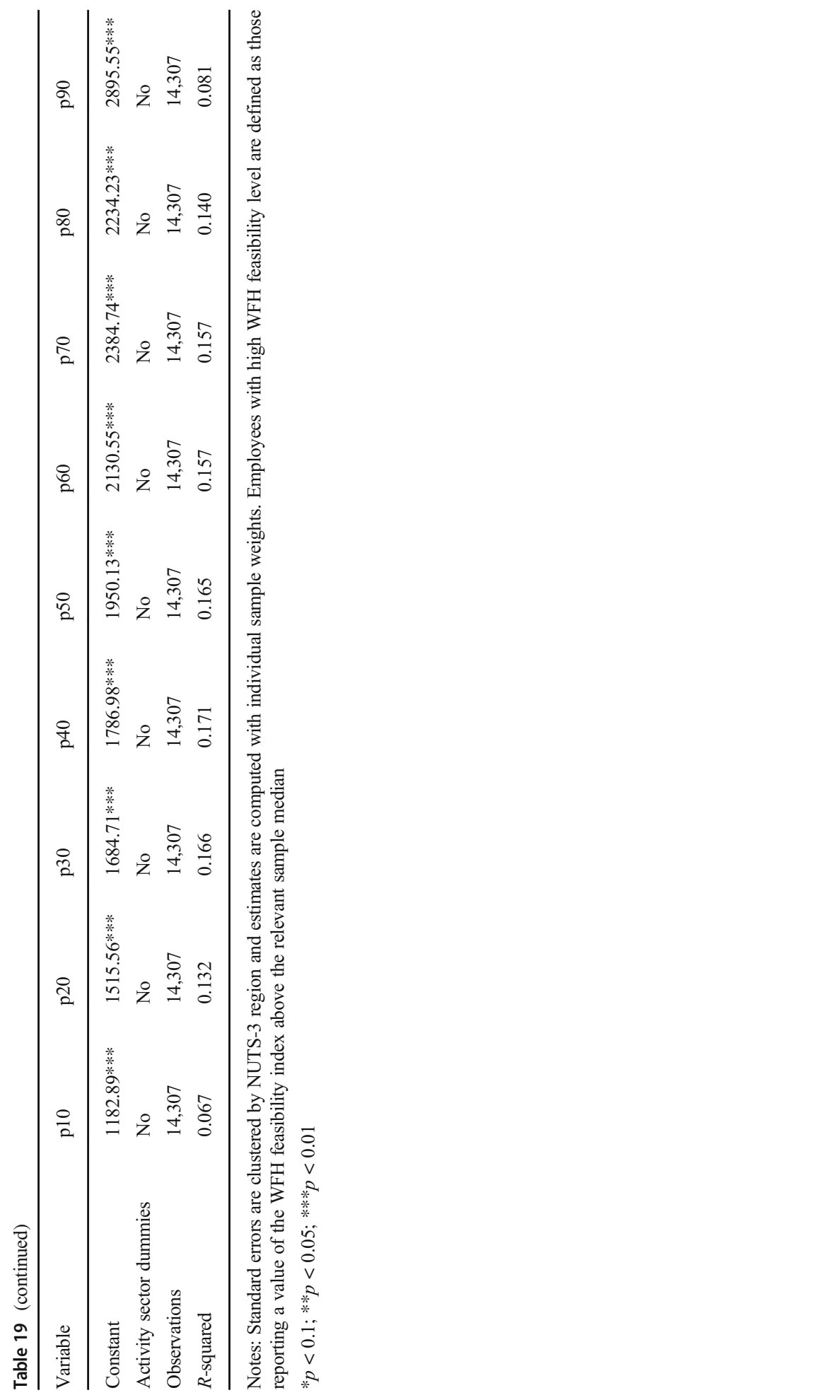




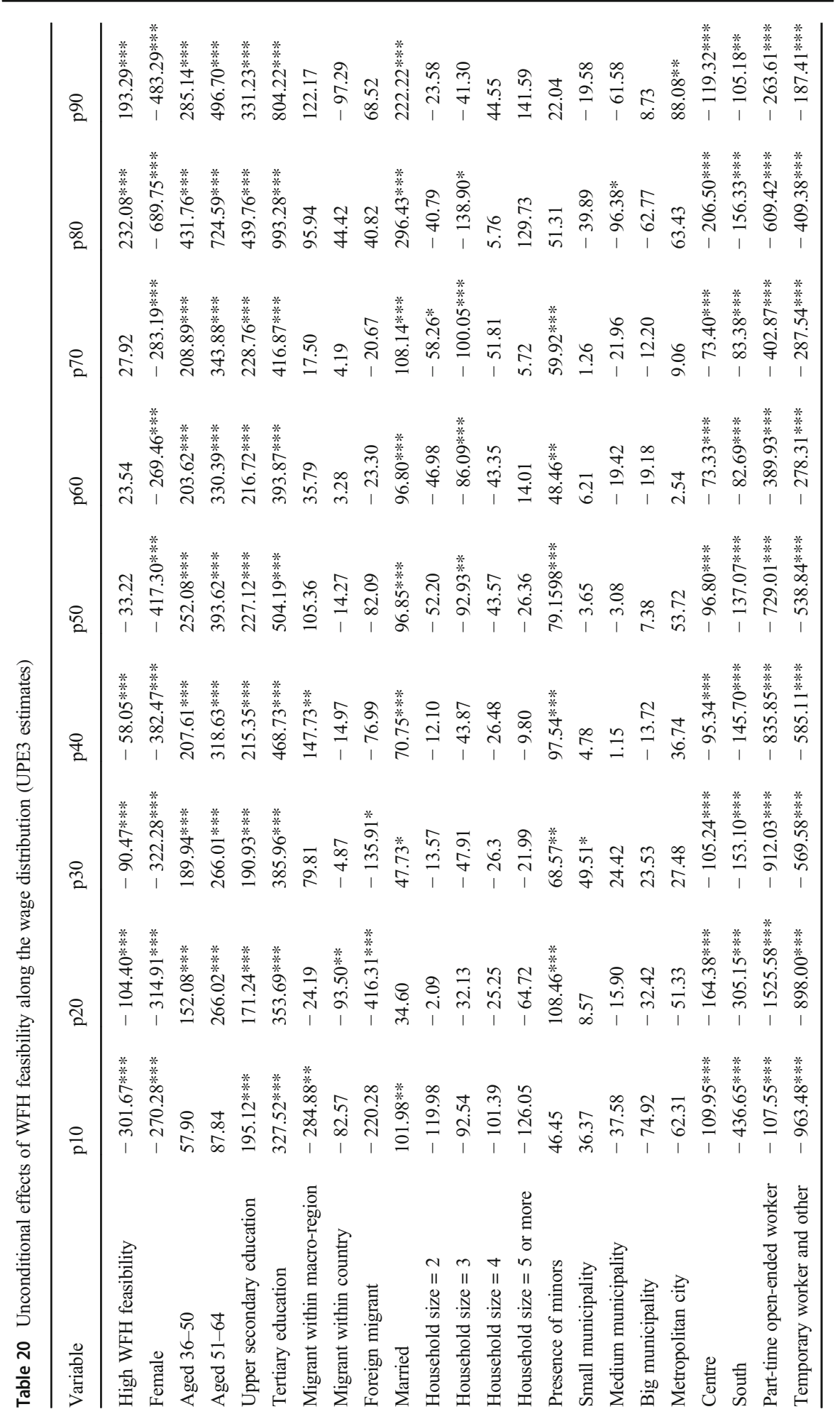




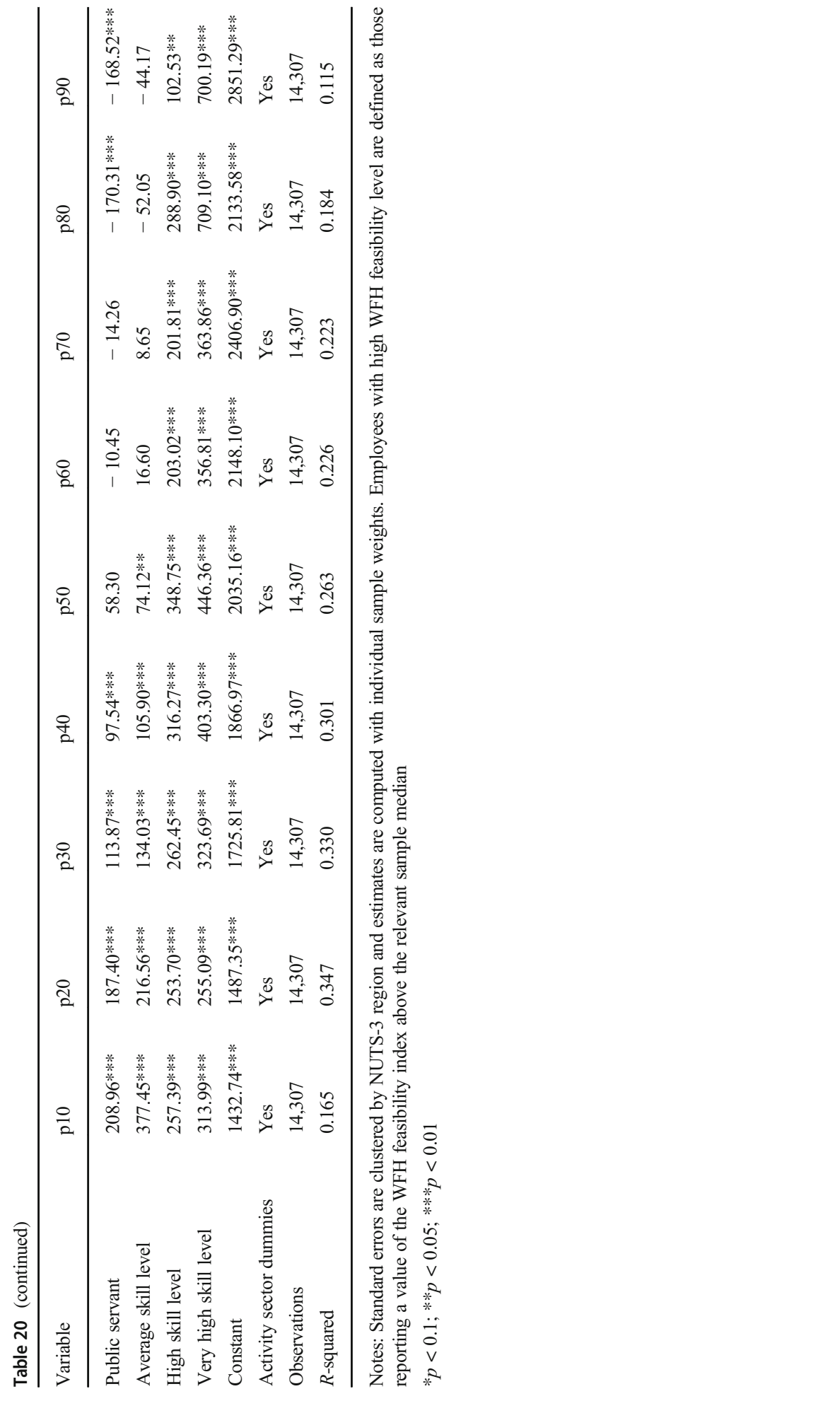


Table 21 Unconditional effects on the mean and Gini index of labour income (with no sample weights)

\begin{tabular}{|c|c|c|c|c|}
\hline \multirow[t]{2}{*}{ Group of employees } & \multicolumn{2}{|l|}{ Mean value } & \multicolumn{2}{|l|}{ Gini index } \\
\hline & UE & UPE & UE & UPE \\
\hline Total sample & $337.14 * * *$ & $149.77 * * *$ & $0.005 * * *$ & $0.002 *$ \\
\hline Male & $558.23 * * *$ & $264.70 * * *$ & $0.004 * *$ & 0.002 \\
\hline Female & 92.61 & 54.98 & $0.003^{* *}$ & 0.000 \\
\hline Aged $25-35$ & $268.87 * * *$ & 66.28 & 0.002 & 0.002 \\
\hline Aged 36-50 & $231.24 * * *$ & 67.97 & 0.003 & 0.001 \\
\hline Aged 51-64 & $515.37 * * *$ & $320.36 * * *$ & $0.007 * * *$ & 0.004 \\
\hline Non-graduated & $243.20 * * *$ & $173.89 * *$ & 0.002 & 0.002 \\
\hline Graduated & $421.00 * * *$ & $221.09 *$ & $0.008 * * *$ & 0.002 \\
\hline Less COVID-19-infected area & $220.27 * * *$ & 36.95 & $0.003 *$ & 0.000 \\
\hline More COVID-19-infected area & $461.43 * * *$ & $268.42 * * *$ & $0.006 * * *$ & $0.004 * *$ \\
\hline
\end{tabular}

Notes: Standard errors are clustered by NUTS-3 region. The table presents coefficients of the variable of interest (i.e. high WFH feasibility) only. Employees with high WFH feasibility level are defined as those reporting a value of the WFH feasibility index over the (non-weighted) sample median (i.e. 53.4). UE estimates are based on a model specification which only includes the variable of interest, while for UPE estimates, additional covariates are included in the model (see Sect. 4)

$* p<0.1 ; * * p<0.05 ; * * * p<0.01$
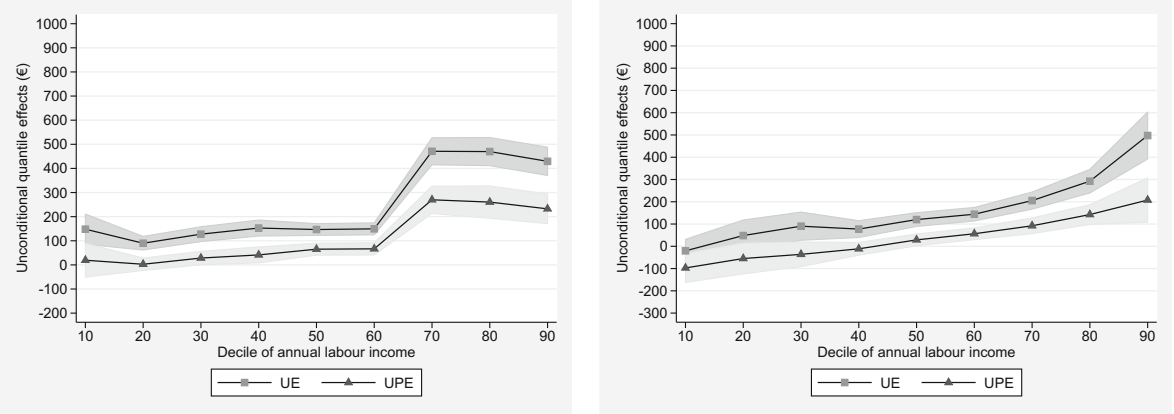

Fig. 10 Unconditional effects along the labour income distribution considering full-time open-ended employees only (left panel) or including self-employees in the sample (right panel). Notes: Standard errors are clustered by NUTS-3 region, and estimates are computed with individual sample weights. Shadowed area reports confidence intervals at $90 \%$ level. The figures present coefficients of the variable of interest (i.e. high WFH feasibility) only. Employees with high WFH feasibility level are defined as those reporting a value of the WFH feasibility index over the sample median (i.e. 52.2 for both samples of workers). UE estimates are based on a model specification which only includes the variable of interest, while for UPE estimates, additional covariates are included in the model (see Sect. 4) 

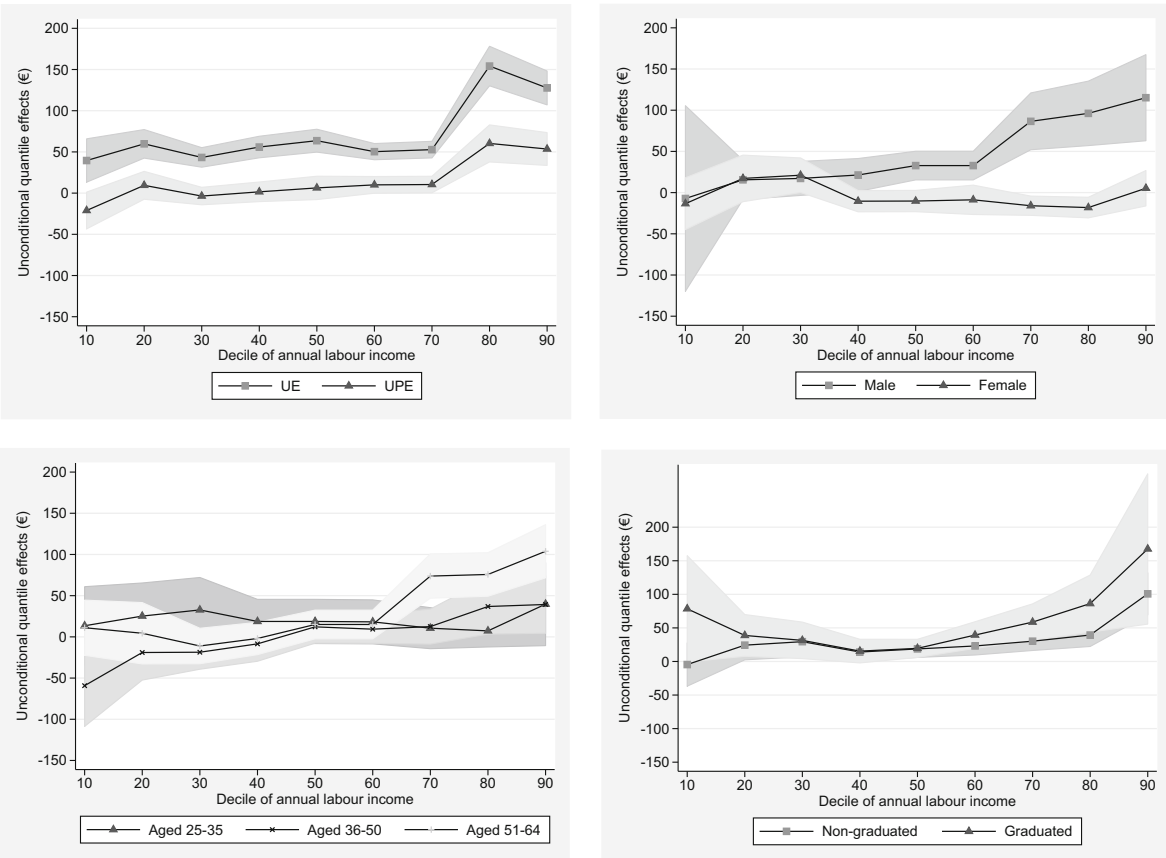

Fig. 11 Unconditional effects along the labour income distribution (variable of interest with continuous specification). Notes: Standard errors are clustered by NUTS-3 region and estimates are computed with individual sample weights. Shadowed area reports confidence intervals at $90 \%$ level. The figures present coefficients of the variable of interest (i.e. WFH feasibility index) only. The WFH feasibility index is a multidimensional index ranging from 0 to 100 . UE estimates are based on a model specification which only includes the variable of interest, while for UPE estimates, additional covariates are included in the model (see Sect. 4). Estimates by employees' characteristics refer to the UPE specification 

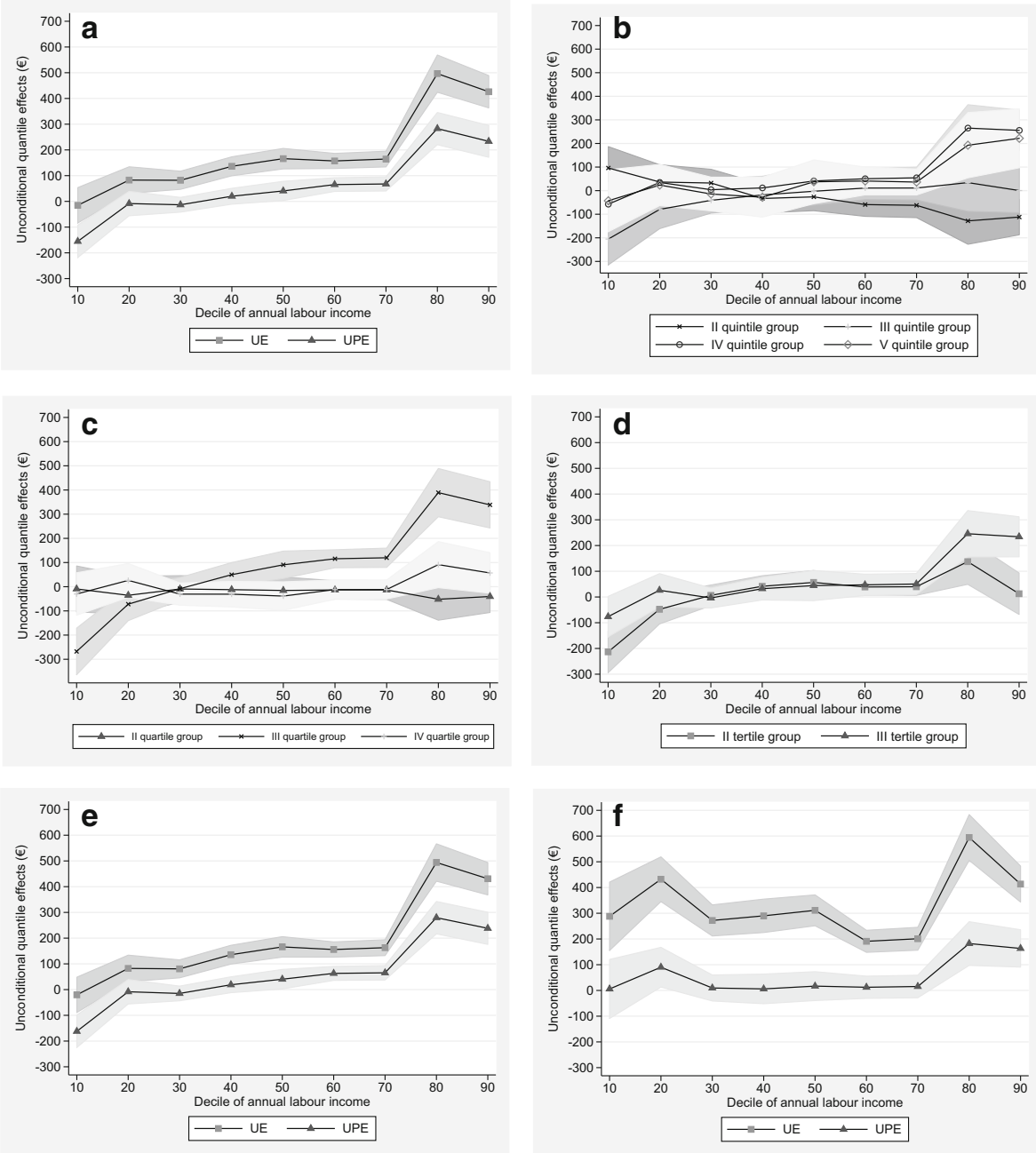

Fig. 12 Unconditional effects along the labour income distribution (variable of interest with other specifications). a Median of the WFH feasibility index (base). b Quintile groups of the WFH feasibility index. c Quartile groups of the WFH feasibility index. d Tertile groups of the WFH feasibility index. e Mean of the WFH feasibility index. f Sixty percent of the mean of the WFH feasibility index. Notes: Standard errors are clustered by NUTS-3 region and estimates are computed with individual sample weights. Shadowed area reports confidence intervals at $90 \%$ level. The figures present coefficients of the variable of interest only, which is defined through different specifications (expressed in panel labels) of the same WFH feasibility index. UE estimates are based on a model specification which only includes the variable of interest, while for UPE estimates, additional covariates are included in the model (see Sect. 4). Estimates in (b), (c), and (d) refer to the UPE specification 

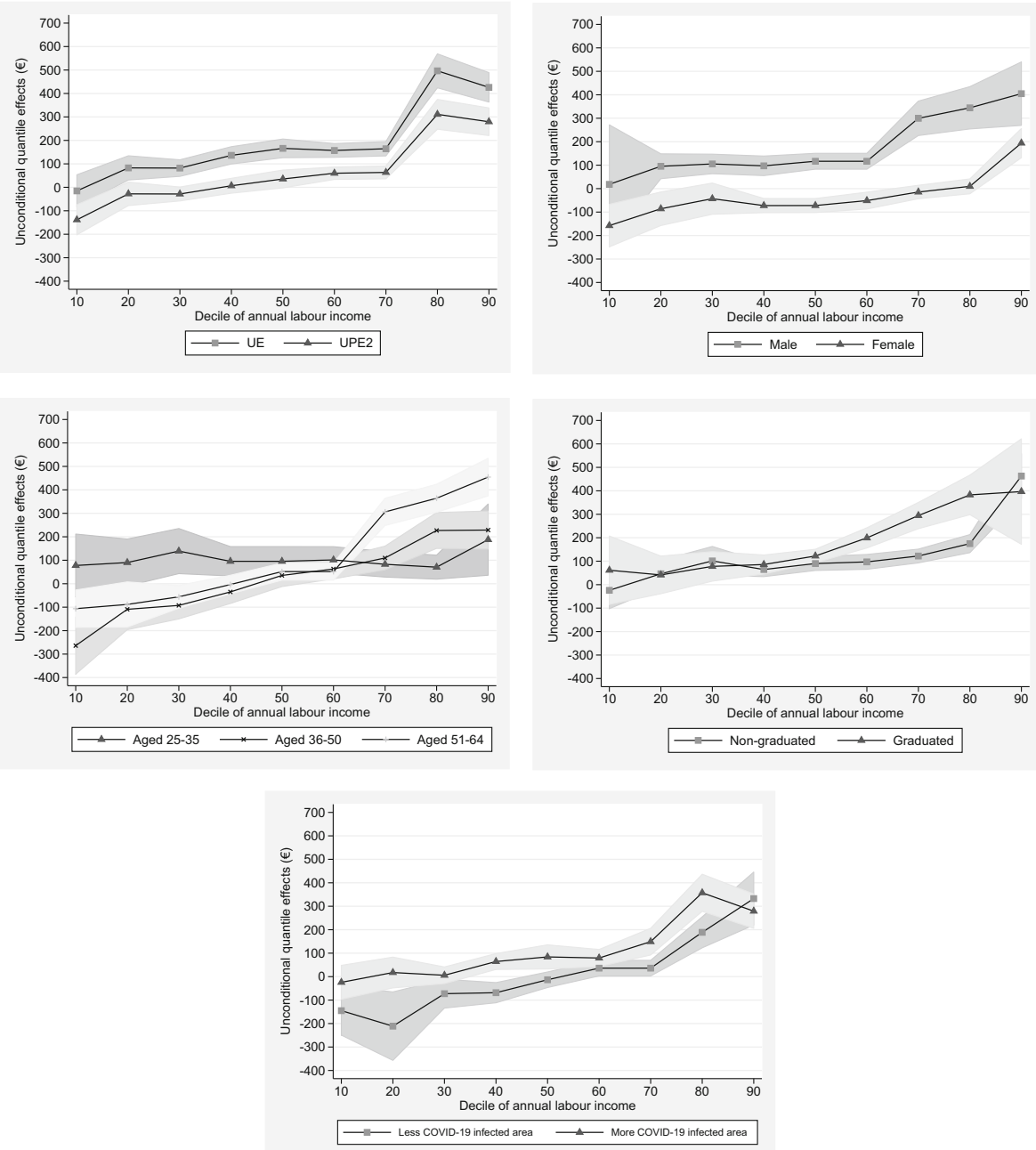

Fig. 13 Unconditional effects of WFH feasibility along the wage distribution (UPE2 estimates). Notes: Standard errors are clustered by NUTS-3 region and estimates are computed with individual sample weights. Shadowed area reports confidence intervals at $90 \%$ level. The figures present coefficients of the variable of interest (i.e. high WFH feasibility) only. Employees with high WFH feasibility level are defined as those reporting a value of the WFH feasibility index above the relevant sample median. UE estimates are based on a model specification which only includes the variable of interest, while for UPE2 estimates, additional covariates demographic characteristics regarding individuals and their households are included in the model (see Sect. 6). Estimates by employees' characteristics refer to the UPE2 specification. Complete estimates for the pooled sample are provided in Appendix Table 19 

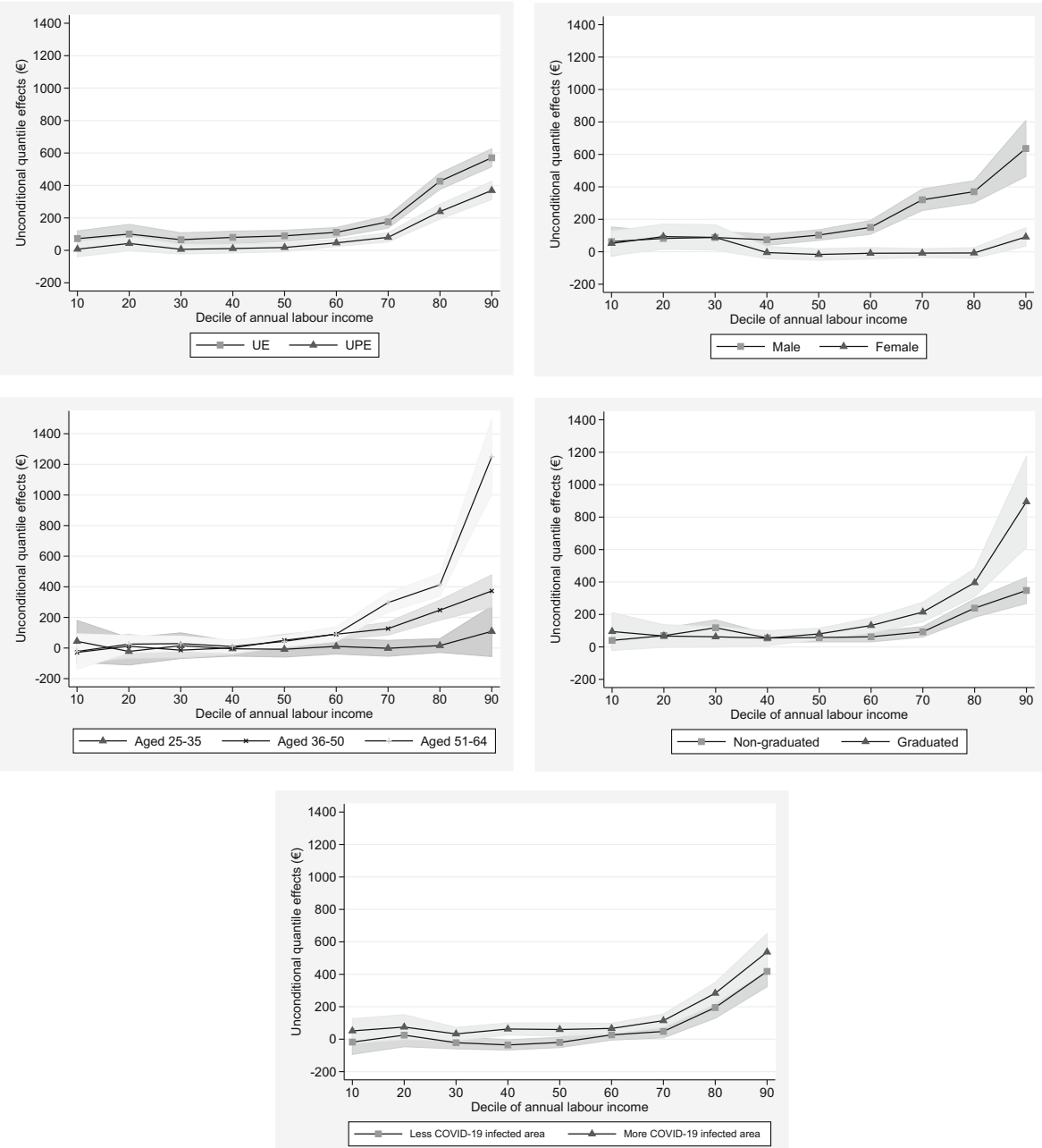

Fig. 14 Unconditional effects of WFH feasibility along the wage distribution (with no sample weights). Notes: Standard errors are clustered by NUTS-3 region. Shadowed area reports confidence intervals at $90 \%$ level. The figures present coefficients of the variable of interest (i.e. high WFH feasibility) only. Employees with high WFH feasibility level are defined as those reporting a value of the WFH feasibility index over the (non-weighted) sample median (i.e. 53.4). UE estimates are based on a model specification which only includes the variable of interest, while for UPE estimates, additional covariates are included in the model (see Sect. 4). Estimates by employees' characteristics refer to the UPE specification

\section{References}

Acemoglu D (1997) Training and innovation in an imperfect labor market. Rev Econ Stud 64(3):445-64 Acemoglu D (2002) Technical change, inequality, and the labor market. J Econ Lit 40:7-72 Acemoglu D (2003) Cross-country inequality trends. Econ J 113(485):F121-FF49 
Acemoglu D, Chernozhukov V, Werning I and Whinston MD (2020) A multi-risk SIR model with optimally targeted lockdown. NBER working paper 27102.

Adams-Prassl A, Boneva T, Golin M, Rauh C (2020) Inequality in the impact of the coronavirus shock: evidence from real time surveys. IZA Discussion Paper No. 13183.

Albanese A, Gallo G (2020) Buy flexible, pay more: the role of temporary contracts on wage inequality. Labour Econ 101814

Albanese A, Picchio M, Ghirelli C (2020) Timed to say goodbye: does unemployment benefit eligibility affect worker layoffs? Labour Econ 65:2020

Alon T, Doepke M, Rumsey J-O, Tertilt M (2020) The impact of COVID-19 on gender equality. In: NBER Working Papers 26947. Inc, National Bureau of Economic Research

Angelici M, Profeta P (2020) Smart-working: work flexibility without constraints. Dondena Working Paper 137

Arntz, Melanie and Sarra, Ben Yahmed and Berlingieri, Francesco (2019), Working from home: heterogeneous effects on hours worked and wages. ZEW - Centre for European Economic Research Discussion Paper No. 19-015. Available at SSRN: https://ssrn.com/abstract $=3383408$ or 10.2139/ssrn.3383408

Atkison BA (eds) (2015) Inequality: what can be done?. Cambridge: Harvard University Press.

Autor DH, Katz LF, Krueger AB (1998) Computing inequality: have computers changed the labor market? Q J Econ 1998(113):1169-1213

Autor DH, Levy F, Murnane JR (2002) Upstairs downstairs: computers and skills on two floors of a large bank. Ind Labor Relat Rev 2002(55):432-447

Autor D, Levy F, Murnane RJ (2003) The skill content of recent technological change: an empirical exploration. Q J Econ 118(4):1279-1333

Baert S Lippens L Moens E Sterkens P Weytjens J (2020a) How do we think the COVID-19 crisis will affect our careers (if any remain)?. GLO Discussion Paper, No. 520, Global Labor Organization (GLO), Essen

Baert S Lippens L Moens E Sterkens P Weytjens J (2020b) The COVID-19 crisis and telework: a research survey on experiences, expectations and hopes. GLO Discussion Paper, No. 532, Global Labor Organization (GLO), Essen.

Barbieri, T., Basso, G., Scicchitano, S., (2020). Italian workers at risk during the COVID-19 epidemic. GLO Discussion Paper, No. 513, Global Labor Organization (GLO), Essen.

Beckfield J (ed) (2019) Unequal Europe: regional integration and the rise of European inequality. Oxford University Press, Oxford

Béland LP, Brodeur A Wright T (2020a) The short term economic consequences of COVID-19: exposure to disease, remote work and government response. GLO Discussion Paper, No. 524, Global Labor Organization (GLO), Essen.

Béland LP, Fakorede O and Mikola D (2020b) The short-term effect of COVID-19 on self-employed workers in Canada. GLO Discussion Paper, No. 585, Global Labor Organization (GLO), Essen

Bélanger F (1999) Workers' propensity to telecommute: an empirical study. Inf Manag 35(3):139-153

Belloc M, Naticchioni P, Vittori C (2019) Urban wage premia, cost of living, and collective bargaining. In: IZA Discussion Papers 12806. Labor Economics (IZA), Institute of

Bennedsen M, Larsen B, Schmutte I, and Scur D (2020) Preserving job matches during the COVID-19 pandemic: firm-level evidence on the role of government aid. GLO Discussion Paper, No. 588, Global Labor Organization (GLO), Essen

Berman E, Bound J, Machin S (1998) Implications of skill-biased technological change: international evidence. Q J Econ 113(4):1245-1279

Bertocchi G and Dimico A (2020) COVID-19, race, and redlining. GLO Discussion Paper, No. 603, Global Labor Organization (GLO), Essen

Bertrand M (2018) Coase lecture: the glass ceiling. Economica 85(338):205-231

Blinder AS, Krueger AB (2013) Alternative measures of offshorability: a survey approach. J Labor Econ 31(S1):S97-S128

Bloom N, Liang J, Robertsand J, Ying ZJ (2015) Does working from home work? Evidence from a Chinese experiment. Q J Econ 130(1):165-218

Boeri T, Caiumi A, Paccagnella M (2020) Mitigating the work-security trade-off. CEPR Press. Covid Economics No 2:60-66

Bonacini L, Gallo G, Patriarca F (2021) Identifying policy challenges of COVID-19 in hardly reliable data and judging the success of lockdown measures. Journal of Population Economics (forthcoming) (this issue)

Brodeur Abel, Gray D, Islam A, Bhuiyan Suraiya J (2020a) A literature review of the economics of COVID19. GLO Discussion Paper, No. 601, Global Labor Organization (GLO), Essen

Brodeur A, Grigoryeva I, Kattan L (2020b) Stay-at-home orders, social distancing and trust. Global Labor Organization Discussion Paper 553 
Brodeur A, Clark AE, Fleche S, Powdthavee N (2020c) COVID-19, lockdowns and well-being: evidence from Google trends. Global Labor Organization Discussion Paper 552

Brynjolfsson E, Horton J, Ozimek A, Rock D, Sharma G, Yi Tu Ye H (2020) Covid-19 and remote work: an early look at U.S. data. NBER Working Paper 27344

Card D, Levine PB (2000) Extended benefits and the duration of UI spells: evidence from the New Jersey extended benefit program. J Public Econ 78(1-2):107-138

Cetrulo A, Guarascio D, Virgillito ME (2019) Anatomy of the Italian occupational structure: concentrated power and distributed knowledge. GLO Discussion Paper 418

Cetrulo A, Guarascio D, Virgillito ME (2020) The privilege of working from home at the time of social distancing. Intereconomics 55:142-147

Checchi D (2006) The economics of education: Human capital, family background and inequality. Cambridge University Press

Chernozhukov V, Fernández-Val I, Melly B (2013) Inference on counterfactual distributions. Econometrica 81(6):2205-2268

Chiou L and Tucker C (2020) Social distancing, Internet access and inequality. NBER Working Papers 26982, National Bureau of Economic Research, Inc.

Choe C, Van Kerm P (2018) Foreign workers and the wage distribution: what does the influence function reveal? Econometrics 6:41

Civil Protection Department (2020) Repository of COVID-19 outbreak data for Italy, 2020. https://github. com/pcm-dpc/COVID-19. [dataset] Accessed 5 May 2020.

Clementi F, Giammatteo M (2014) The labour market and the distribution of earnings: an empirical analysis for Italy. Int Rev Appl Econ 28(2):154-180 2014

Delaporte I Peña W (2020) Working from home under COVID-19: who is affected? Evidence from Latin American and Caribbean Countries. GLO Discussion Paper, No. 528, Global Labor Organization (GLO), Essen

Depalo D (2021) True Covid-19 mortality rates from administrative data. Journal of Population Economics (forthcoming), (this issue).

Di Nardo J, Fortin N, Lemieux T (1996) Labour market institutions and the distribution of wages 1973-1992. A semiparametric approach. Econometrica 64:1001-1024. https://doi.org/10.2307/2171954

Dingel J, Neiman B (2020) How many jobs can be done at home? National Bureau of Economic Research No 26948

Dosi G, Guarascio D, Ricci A, Virgillito ME (2019) Neodualism in the Italian business fi rms: training, organizational capabilities, and productivity distributions. Small Bus Econ

Duman, Anil (2020) Wage losses and inequality in developing countries: labor market and distributional consequences of Covid-19 lockdowns in Turkey. GLO Discussion Paper, No. 602, Global Labor Organization (GLO), Essen

Dutcher EG and Saral KJ (2012) Does team telecommuting affect productivity? An experiment. MPRA Paper No. 41594, University Library of Munich.

Eurofound and the International Labour Office (2017) Working anytime, anywhere: the effects on the world of work. Publications Office of the European Union, Luxembourg, and the International Labour Office, Geneva.

Favero CA, Ichino A and Ustichini A (2020) Restarting the economy while saving lives under COVID-19. CEPR Discussion paper No. 14664.

Filippetti A, Guy F, Iammarino S (2019) Regional disparities in the effect of training on employment. Regional Studies 53(2):217-230. https://doi.org/10.1080/00343404.2018.1455177

Firpo S (2007) Efficient semiparametric estimation of quantile treatment effects. Econometrica 75(1):259-276

Firpo S, Fortin NM, Lemieux T (2009) Unconditional quantile regressions. Econometrica 77:953-973

Fortin N, Lemieux T, Firpo S (2011) Decomposition methods in economics. Handbook of Labor Economics 4:1-102

Freeman RB, Katz LF (eds) (1995) Differences and changes in wage structures. The University of Chicago Press, Chicago

Fruman J (2020) US unemployment insurance in the pandemic and beyond, PIIE Policy Brief, 20-10

Gaeta GL, Lubrano Lavadera G and Pastore F (2018) Overeducation wage penalty among Ph.D. holders. An unconditional quantile regression analysis on Italian data. GLO Discussion Paper Series 180, Global Labor Organization (GLO).

Gallo G, Pagliacci F (2020) Widening the gap: the influence of 'inner areas' on income inequality in Italy. Econ Polit 37:197-221

Gariety BS, Shaer S (2007) Wage differentials associated with working at home. Monthly Lab Rev 130:61-67

Goldin C (2014) A grand gender convergence: its last chapter. Am Econ Rev 104(4):1091-1119 
Goos M, Manning A, Salomons A (2014) Explaining job polarization: Routine-biased technological change and offshoring. Am Econ Rev 104(8):2509-2526. https://doi.org/10.1257/aer.104.8.2509

Gottlieb C, Jan G, Poschke M (2020) Working from home across countries. CEPR Covid Economics: Vetted and Real-Time Papers 8:70-91

Gottschalk P, Smeeding TM (1997) Cross-national comparisons of earnings and income inequality. J Econ Lit 35(3):633-687

Greyling T, Rossouw S and Adhikari T (2020) A tale of three countries: how did Covid-19 lockdown impact happiness?. GLO Discussion Paper, No. 584, Global Labor Organization (GLO), Essen

Hampel FR (1974) The influence curve and its role in robust estimation. J Am Stat Assoc 69:383-393

Hensvik L, Le Barbanchon T, Rathelot R (2020) Which jobs are done from home? evidence from the American time use survey. IZA Discussion Paper 13138

Hill, E.J., Miller, B.C., Weiner, S.P. and Colihan, J. (1998), Influences of the virtual office on aspects of work and work/life balance. Personnel Psychology, Vol. 51 p. 1.

Holgersen H, Zhiyang J, Svenkerud S (2020) Who and how many can work from home? Evidence from task descriptions and Norwegian job advertisements. (April 20, 2020). Available at SSRN: https://ssrn. com/abstract $=3580674$ or. https://doi.org/10.2139/ssrn.3580674

Hornbeck, R. and Moretti, E. (2018). Who benefits from productivity growth? The direct and indirect effects of local TFP growth on wages, rents, and inequality. NBER working paper 24661.

Ichino P (2020a) Se l'epidemia mette le ali allo smart working, www.lavoce.info.

Ichino P. (2020b) Un'idea sbagliata dello smart working, www.lavoce.info.

Koenker R, Bassett G (1978) Regression quantiles. Econometrica 46(1):33-50

Koren M, Peto R (2020) Business disruptions from social distancing. In: Covid Economics, (2) 13-31. Press, CEPR

Krueger AB (1993) How computers have changed the wage structure: evidence from microdata, 1984-1989. Q J Econ 108(1):33-60

Lalive R, van Ours JC, Zweimüller J (2006) How changes in financial incentives affect the duration of unemployment. Rev Econ Stud 73(4):1009-1038

Lehmann EL and Romano JP (2005) Testing statistical hypotheses, 3rd edn., Springer.

Leibovici F, Santacrue AM, Famiglietti M (2020) Social distancing and contact-intensive occupations. St. Louis Federal Reserve Bank - On the Economy Blog, March

Leonida L, Marra M, Scicchitano S, Giangreco A, Biagetti M (2020) Estimating the wage premium to supervision for middle managers in different contexts: evidence from Germany and the UK, in Work, Employment \& Society. First Published May 4:2020. https://doi.org/10.1177/0950017020902983

Leslie LM, Manchester CF, Park T-Y, Mehng SA (2012) Flexible work practices: a source of career premiums or penalties? Acad Manag J 55(6):1407-1428

Leung K, Wu JT, Liu D, Leung GM (2020) First-wave COVID-19 transmissibility and severity in China outside Hubei after control measures, and second-wave scenario planning: a modelling impact assessment. Lancet 395:1382-1393. https://doi.org/10.1016/S0140-6736(20)30746-7

Meliciani V, Radicchia D (2011) The informal recruitment channel and the quality of job-worker matches: an analysis on Italian survey data. Ind Corp Chang 20(2):511-554 2011

Meliciani V, Radicchia D (2016) Informal networks, spatial mobility and overeducation in the Italian labour market. Ann Reg Sci 56(2):513-535 2016

Milani F (2021) COVID-19 outbreak, social response, and early economic effects: a global VAR analysis of cross-country interdependencies. J Popul Econ (forthcoming), (this issue).

Mongey S, Pilossoph L, Weinberg A (2020) Which workers bear the burden of social distancing policies?. NBER Working Paper No. 27085.

Nikolova M and Popova O (2020) Sometimes your best just ain't good enough: The worldwide evidence on subjective well-being efficiency. GLO Discussion Paper, No. 596, Global Labor Organization (GLO), Essen

OECD (2020) Tackling coronavirus (COVID-19): contributing to a global effort. https://www.oecd. org/coronavirus/country-policy-tracker/

Otsu T, \& Taniguchi G (2020) Kolmogorov-Smirnov type test for generated variables. Economics Letters (in press). Available online 21 July 2020, https://doi.org/10.1016/j.econlet.2020.109401

Pabilonia SW, Vernon V (2020) Telework and time use in the United States. GLO Discussion Paper, No. 546, Global Labor Organization (GLO), Essen

Papanikolaou D and Schmidt LDW (2020) Working remotely and the supply-side impact of Covid-19. Working Paper 27330. Series: Working Paper Series. National Bureau of Economic Research, June 2020. doi: 10.3386/w27330. url: http://www.nber.org/papers/w27330 (visited on 06/15/2020). 
Picchio M, Mussida C (2011) Gender wage gap: a semi-parametric approach with sample selection correction. Labour Econ 18:564-578

Pigini C, Staffolani S (2019) Teleworkers in Italy: who are they? Do they make more? Int J Manpow 40(2): 265-285

Pouliakas K (2020) Working at home in Greece: unexplored potential at times of social distancing? IZA DP No. 13408

Qiu Y, Chen X, Shi W (2020) Impacts of social and economic factors on the transmission of coronavirus disease 2019 (COVID-19) in China. J Popul Econ 2020:1127-1172. https://doi.org/10.1007/s00148-02000778-2

Regoli A, D’Agostino A, Grandner T, Gstach D (2019) Accounting for the permanent vs temporary wage gaps among young adults: Three European countries in perspective. International Labour Review 158(2): 337-364. https://doi.org/10.1111/ilr.12075

Rothe C (2010) Nonparametric estimation of distributional policy effects. J Econ 155:56-70

Scicchitano S, Biagetti M, Chirumbolo A (2020) More insecure and less paid? The effect of perceived job insecurity on wage distribution. Appl Econ 52(18):1998-2013

Shierholz B H (2020) More Than Three Months in, Job Losses Remain at Historic Levels. Working Economics Blog, June 25. Washington: Economic Policy Institute

Tiraboschi M (2017) Il lavoro agile tra legge e contrattazione collettiva: la tortuosa via italiana verso la modernizzazione del diritto del lavoro. WP CSDLE "Massimo DAntona" 335

Van Ours JC, Vodopivec M (2006) How shortening the potential duration of unemployment benefits affects the duration of unemployment: evidence from a natural experiment. J Labor Econ 24(2):351-378

Van Reenen J (1997) Employment and technological innovation: evidence from U.K. Manufacturing Firms. J Labor Econ 1997(15):255-284

Weeden KA (2005) Is there a flexiglass ceiling? Flexible work arrangements and wages in the United States. Soc Sci Res 34(2):454-482

Yasenov V (2020) Who can work from home?, IZA DP No. 13197, April 2020.

Zimmermann KF, Karabulut G, Huseyin Bilgin M and Cansin Doker A (2020) Inter-country distancing, globalization and the coronavirus pandemic, the world economy, 43:1484-1498.

Publisher's note Springer Nature remains neutral with regard to jurisdictional claims in published maps and institutional affiliations. 